\title{
Research Paper \\ Risk Factors of Anxiety in Children and Adolescents with Autism Spectrum Disorder: A Systematic Review
}

\section{Samaneh Behzadpoor ${ }^{1}$, Hamidreza Pouretemad ${ }^{2}$, Saied Akbari Zardkhaneh ${ }^{* 3}$}

1. Ph.D. in Clinical Psychology, Faculty of Education and Psychology, Shahid Beheshti University, Tehran, Iran 2. Professor, Department of Psychology, Faculty of Education and Psychology, Shahid Beheshti University, Tehran, Iran 3. Assistant Professor, Department of Psychology, Faculty of Education and Psychology, Shahid Beheshti University, Tehran, Iran

Citation: Behzadpoor S, Pouretemad H, Akbari Zardkhaneh S. Risk factors of anxiety in children and adolescents with autism spectrum disorder: a systematic review. J Child Ment Health. 2021; 7(4): 165-180.

URL: http://childmentalhealth.ir/article-1-781-en.html
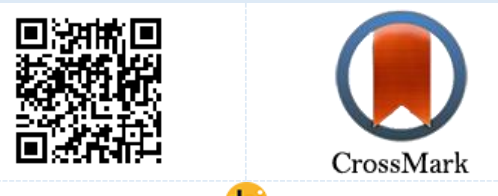

do: $10.52547 /$ jemh.7.4.11

20.1001 .1 .24233552 .1399 .7 .4 .14 .2

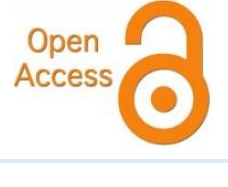

\section{A R T I C L E I N F O}

Keywords:
Autism spectrum
disorder (ASD),
anxiety,
risk factors

Received: 7 Feb 2019

Accepted: 4 Sep 2019

Available: 18 Mar 2021

\begin{abstract}
A B S T R A C T
Background and Purpose: As children and adolescents with autism spectrum disorder (ASD) are more likely to experience anxiety than their peers, investigation of risk factors for anxiety in them is important for the purpose of diagnosis and treatment. Thus, this study aims to explore the risk factors of anxiety in children and adolescent with ASD.

Source of Data: To obtain the selected articles to enter the analysis, systematic search strategies were used. The five databases including Scopus, Sciencedirect, PubMed, OVID-PsycINFO, and Springer were searched using a combination of selected keywords.

Method: This study was a systematic review and 5 electronic databases from 2000 to 2019 were searched using a comprehensive search strategy. As a result of this search, 377 articles were retrieved. According to PRISMA and based on the inclusion and exclusion criteria, 18 research papers were selected for the study.

Results: Although the findings were somehow contradictory, according to the results of the majority of studies, it can be concluded that anxiety in girls and in older children and adolescents with ASD is higher than boys and younger children and adolescents with ASD. Moreover, it was found that children with higher cognitive functions, lower autism severity, and more social problems had more anxiety symptoms.

Conclusion: The current findings suggest that gender, age, cognitive functioning, ASD severity, and social problems should be considered as potential risk factors for anxiety when assessing a child with ASD. Therefore, early prevention and intervention of anxiety in children with ASD who are most at risk is necessary.
\end{abstract}

* Corresponding author: Saied Akbari Zardkhaneh, Assistant Professor, Department of Psychology, Faculty of Education and Psychology, Shahid Beheshti University, Tehran, Iran.

E-mail: S_Akbari@bu.ac.ir

Tel: (+98) 2129905382

2476-5740/ (C) 2021 The Authors. This is an open access article under the CC BY-NC-ND license

(https://creativecommons.org/licenses/by-nc-nd/4.0/). 


\section{Extended Abstract}

\section{Introduction}

Autism spectrum disorder (ASD) is defined by a deficit in social interaction along with the presence of repetitive and/or restricted interests and/or behaviors (1). In addition to these main symptoms, researchers have reported that 11 to $84 \%$ of children and adolescents with autism experience some degrees of anxiety $(2,3)$. Researchers have argued that the representation and occurrence of anxiety in autism can be a function of some risk factors such as age of the child, cognitive and linguistic abilities, etc. that can affect both the occurrence and representation of anxiety (19-21). Research on normal children has also shown that there are some risk factors for anxiety. For example, gender is one of these risk factors (28), and the prevalence of anxiety in girls is reported to be higher than the boys (29).

On the other hand, research shows that the relationship between anxiety and autism profile can be reciprocal (32). This theory states that anxiety can not only lead to consequences and problems in children with autism, but some characteristics of children with autism can exacerbate anxiety symptoms $(20,33)$. Accordingly, several potential risk factors for anxiety in autism have been suggested in the literature $(6,13,34)$. However, results of the research are contradictory (27) and require conducting review researches to integrate the studies and present a single perspective (6). Therefore, this study aimed to investigate the literature to explore the risk factors for anxiety in children and adolescents with ASD.

\section{Method}

To address the purpose of this study, a systematic review method was used to integrate and present the findings of different researches. The statistical population of this systematic study included all research articles on correlations and risk factors of anxiety in children and adolescents with ASD, which were published in reliable scientific journals from 2000 to 2019. To obtain selected articles to enter the analysis, systematic search strategies were used. The five databases including Scopus, Sciencedirect, PubMed, OVID-PsycINFO, and Springer were searched using a combination of selected keywords. Inclusion and exclusion criteria were determined according to the purpose of the research to screen the retrieved articles. Inclusion criteria were original articles (1) about anxiety risk factors, predictors, and correlations in children and adolescents with ASD, (2) published between 2000 and 2019, and (3) in English. Exclusion criteria also included articles whose sample groups were not children or adolescents, and the full text of which was not available.

Based on the searche in the mentioned databases, a total of 654 articles were retrieved. After removing duplicate articles and screening articles based on the PRISMA flow diagram, 20 articles were entered into the final analysis. To ensure the quality of the selected articles, all steps of search, screening and final selection of articles were performed by two independent researchers, both of whom were Ph.D. students in psychology.

\section{Results}

Five risk factors identified from selected articles included:

Gender: Only two studies reported that anxiety is more prevalent in girls than boys $(6,35)$, and one study did not recognized gender differences to be a risk factor for anxiety (36).

Age: Some studies have suggested that age positively predicts anxiety in children and adolescents with autism spectrum disorder (e.g., 13, 16, 34, 36-38). Other studies have reported that there is no relationship between age and anxiety in children with ASD (e.g. 39-40). Among the studies reviewed in this study, only one research (6) suggested that anxiety was more prevalent among younger than older children with ASD.

Cognitive functioning: Many studies (13, 16, 34, 37, $40,43)$ have concluded that anxiety is more prevalent in children with higher intelligence. However, some studies $(39,44)$ found no relationship between intelligence and anxiety levels in children and adolescents with ASD. In addition, Hollocks et al. (45) examined the relationship between anxiety and executive functions in children and adolescents with autism and showed that there 
was a positive relationship between poor executive functions and anxiety.

ASD symptom severity: There are contradictory data regarding the relation between the severity of ASD and anxiety. Some researchers have reported that higher levels of anxiety were linked with greater ASD symptom severity $(37,38,40,42,46)$, and some research failed to find a link between ASD severity and anxiety $(39,44)$. On the other hand, some research showed that children with more ASD symptomatology may be less vulnerable to anxiety disorders $(13,16,41,47-49)$.

Social problems: Regarding the relationship between social problems and anxiety, although one study did not find a relationship between social deficits and anxiety in children and adolescents with autism spectrum disorder (39), one study reported an inverse relationship between social problems and anxiety (40). On the other hand, some studies have reported a positive relationship between social problems and the severity of anxiety $(34,36,41,50)$.

\section{Conclusion}

In this study, 5 factors were identified as risk factors and predictors of anxiety, namely gender, age, cognitive abilities, the severity of autism symptoms, and social problems. However, the findings of studies were somewhat contradictory. Totally, the findings show that some characteristics in children and adolescents with autism can predispose them to anxiety, and given the contradictory findings of research, further investigation is needed. It is noteworthy that the studies used different age groups with different characteristics (for example, different gender and level of intelligence) that increase heterogeneity between children and adolescents and can produce different results. Also, studies used different measures and methods, which can be another reason for the contradictory findings.

It is suggested to perform more research in this field with a larger sample size as well as a more homogeneous sample group to investigate other risk factors for anxiety in autism. Limited access to some databases such as PsycINFO, Cochrane, etc. Caused the present study to be conducted in only five databases, which is one of the limitations of the present study.

\section{Ethical Considerations}

Compliance with ethical guidelines: This article was extracted from the Ph.D. dissertation of the first author, which was approved in ethical committee of Shahid Beheshti University, with the code IR.SBU.REC.1398.023.

Funding: This study was conducted without the financial support of any public or private institution or organization

Authors' contribution: The first author conducted the research. Second and third authors provided academic support, including research methodology, conceptual development and guidance on the research process. The final manuscript was approved by all authors.

Conflict of interest: No conflict of interest was reported by scholars.

Acknowledgments: All the individuals who made contribution in conducting this study are highly appreciated. 


\section{عوامل خطرسازٍ اضطر اب در كودكان و نوجوانان با اختلال طيف اوتيسم: مرورى نظاممند}

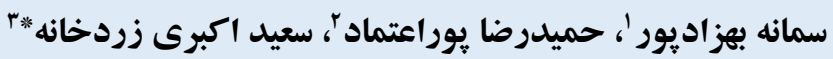

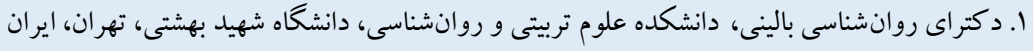

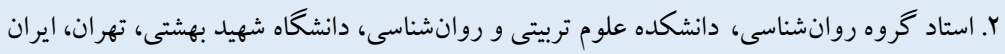

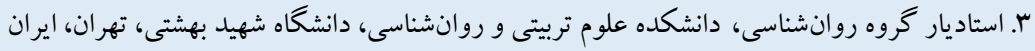

زمينه و هدف: از آنجايى كه كود كان و نوجوانان با اختلال طيف اوتيسم احتمالاً اضطراب بيشترى نسبت به ساير همسالان تجربه مى كنند،

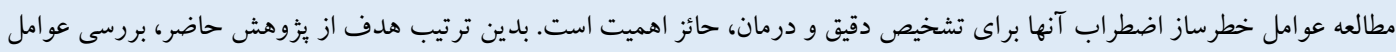

$$
\text { خطرساز اضطر اب در كود كان و نوجوانان با اختلال طيف اوتيسم بود. }
$$

مشخصات مقاله

منابع دادهها: براى به دست آوردن مقالات منتخب جهت ورود به تحليل، از راهبرد جستجوى نظاممند استفاده شد. بنج بِايخاه اطلاعاتى شادن Scopus

شدند.

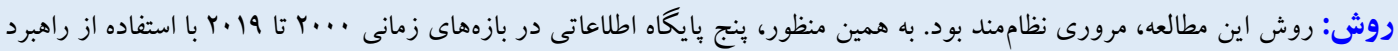

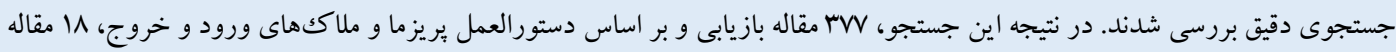
براى ورود به يُزوهش انتخاب شدند.

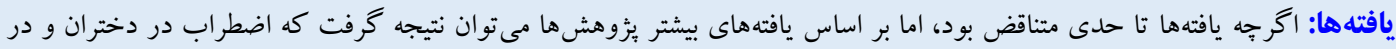

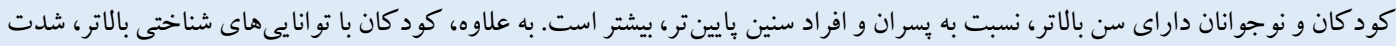

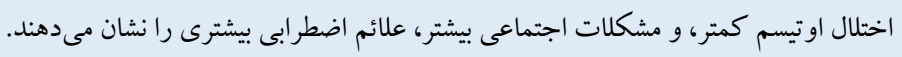

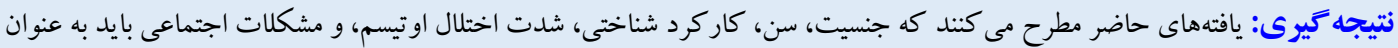

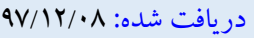

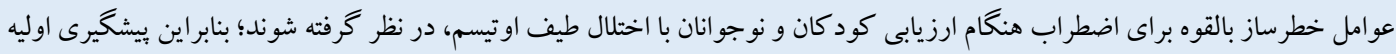

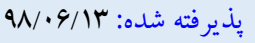


اجتماعى، ترس از تغيير و ترسهاى غيرمعمول، از مشـخههاى مشتر كـ

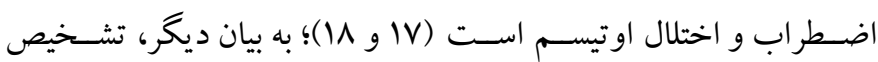

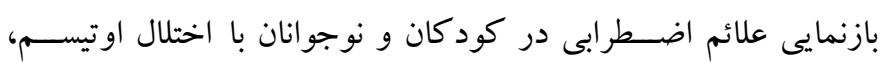

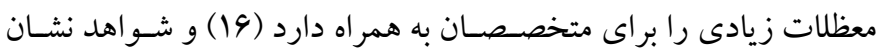

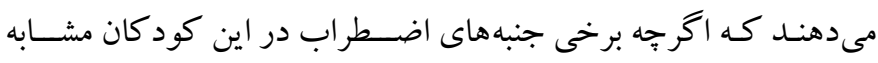

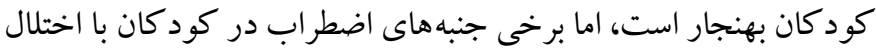

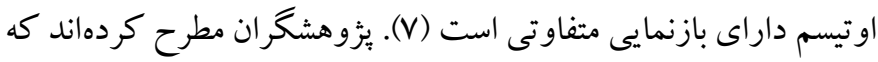

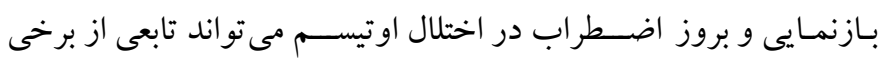

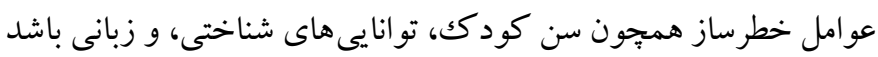

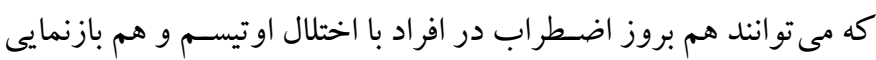
آن راتحت تأثير قرار دهند (19-19) تحول شناختى يكى از عواملى است كه در كود كان با اختلال اوتيسم،

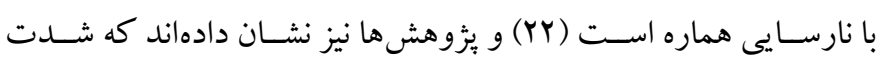

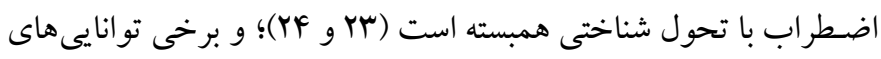

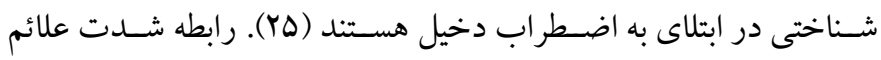
اوتيسم و اضطر اب نيز در برخى يزوهش ها بر برسى شدهاند كه نتايج آنها

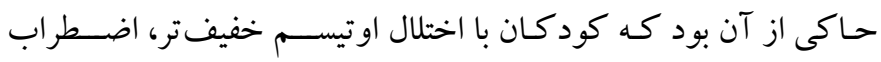

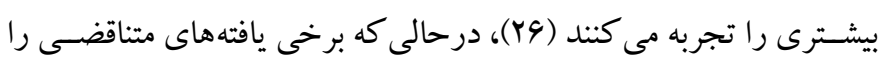

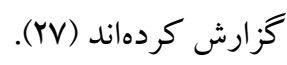
يُوهش هاى انجام شده در كود كان به تحول بهنجار نيز نشان دادهاند كه برخى عوامل خطرسـاز براى ابتلاى به اضطر اب وجود دارد. بر ایى مثال

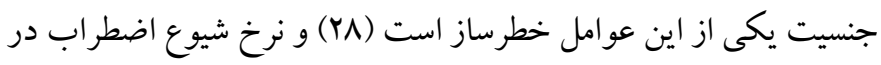

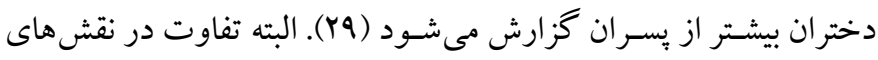
جنسـيتى و نيز سـاختار متفاوت مغز در پِسـران و دختران تا حدى شـيوع

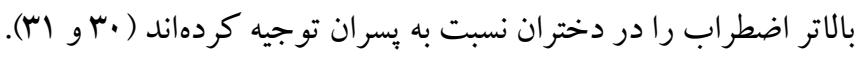
از سـوى ديخر، بزوهش هاى انجام شـده نشـان مى دهند كه رابطه بين

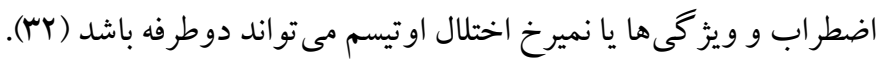

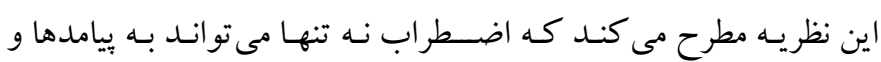

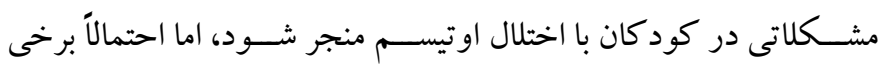

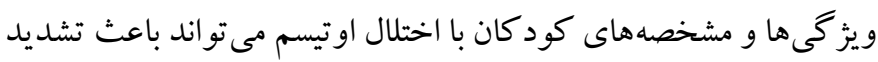
علائم اضطر اب شده و بروز اضطراب را محتمل تر كنند و عو امل خطرساز

\section{مقلممه}

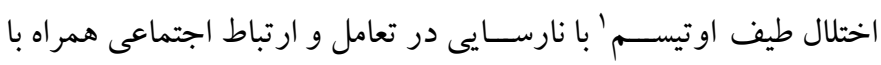
رفتارها و علايق تكرارى و محدود مشــخص مى شـــود (1). علاوه بر اين

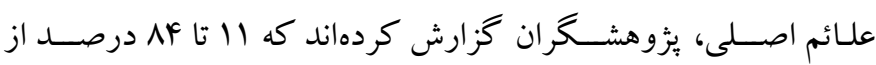

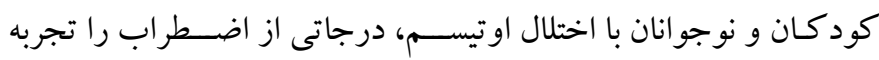

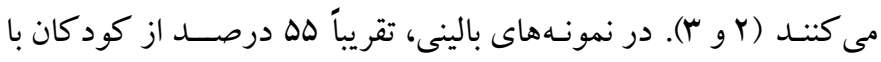

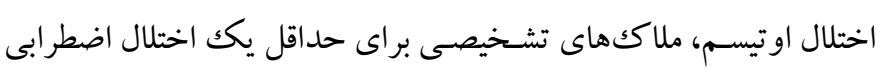

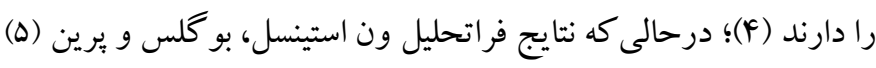

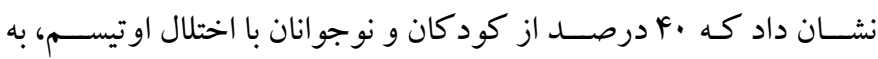

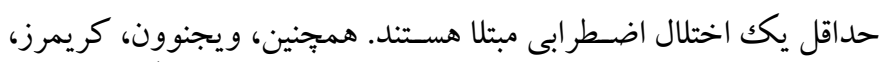

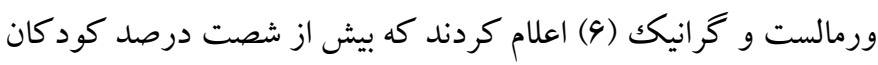
اين كود كان بر اساس فرمهاى خود گز ارشى، و بيش از هشتاد درصد آنها

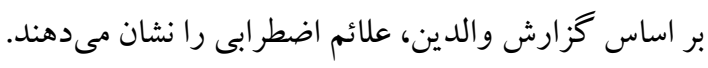
اضطراب همبود در كود كان با اختلال طيف اوتيسم مى تو اند بريشانى

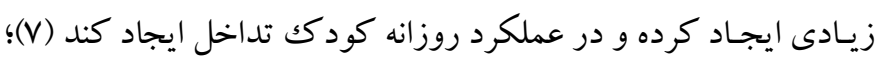

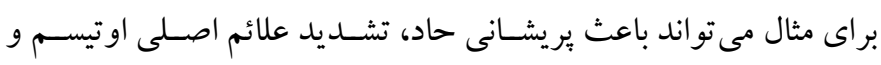

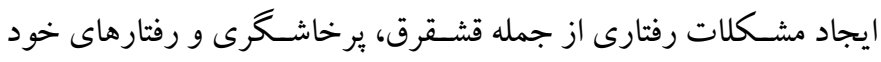

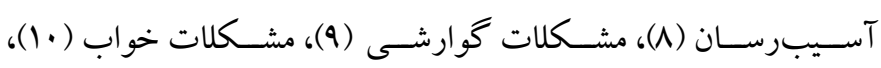

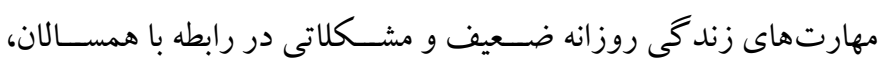

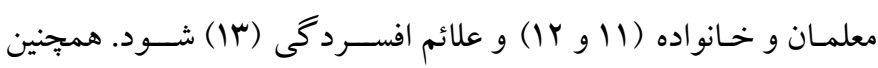

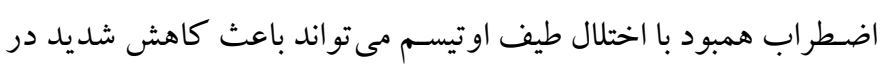
كيفيت زند

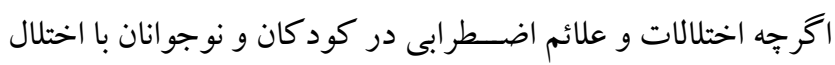

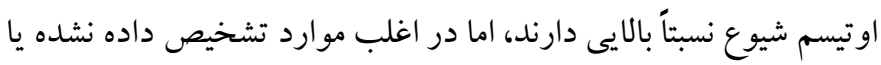

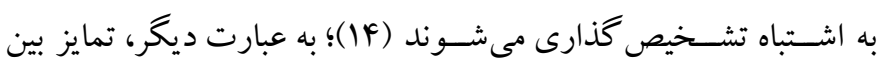

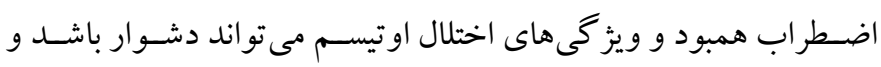

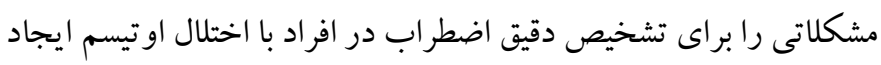

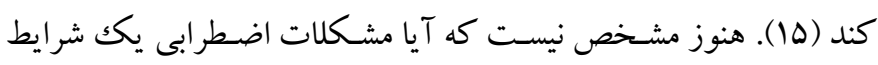

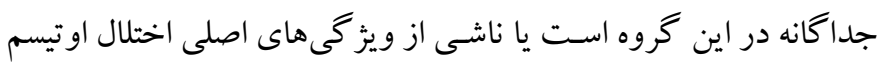

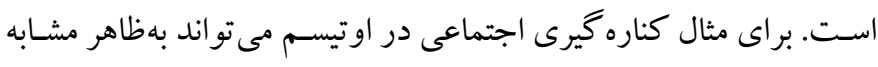

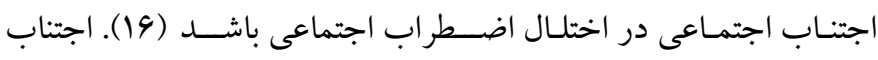




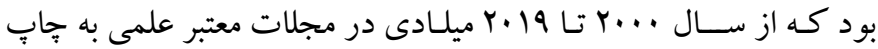

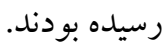

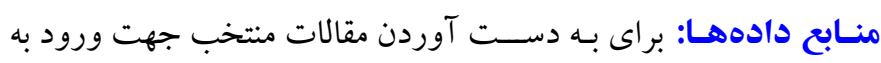

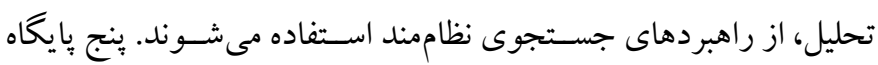

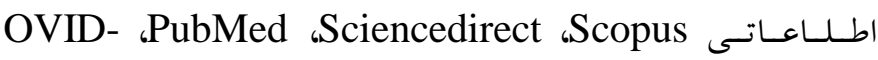
PsycINFO با اســفاده از تر كيبى از كليدوازمهاى زير Springer

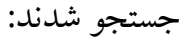

("Autistic Disorder*” OR "Autism spectrum disorder*” OR "Pervasive developmental disorder*" OR "Asperger Syndrome" OR autism OR "ASD" OR "PDD") AND) anxiety OR worry OR "internalized disorder" OR stress OR "anxious") AND ("risk factor*" OR correlate* OR associate* OR predictor* OR "risk component")

روش وارسـى مقالات: ملاككهاى ورود و خروج متناسـبـ با هدف ئزوهش، براى غربال كردن مقالاتى كه بازيابى مى شـوند، تنظيم مى شـود.

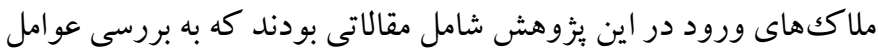

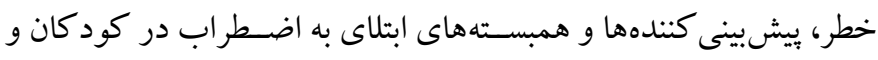

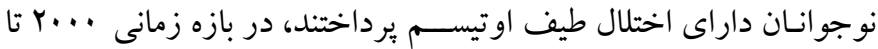

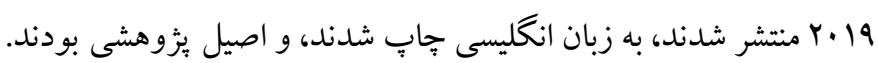

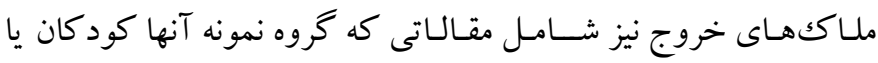

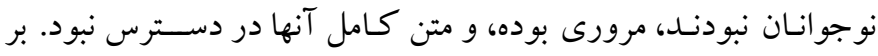

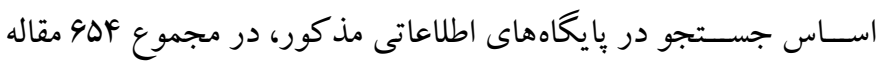

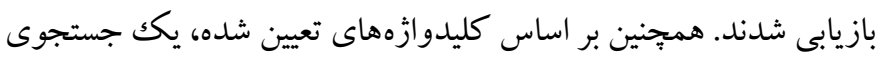

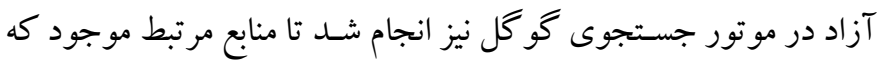
از بايڤاههاى مذكور بازيابى نشدهاند نيز به مقالات افزوده شوند. همجنين رفرنس هاى منابع بازيابى شــده نيز بررسـى شـــند تا مقالات مرتبط وارد

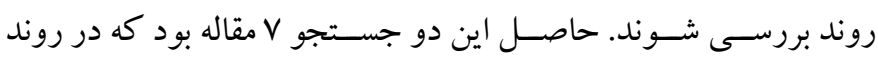

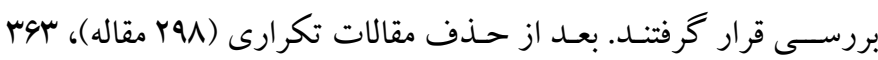

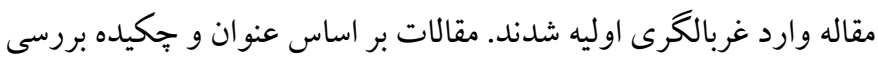

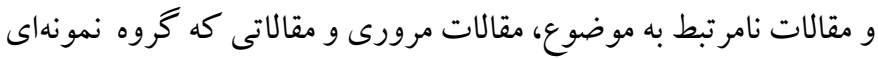

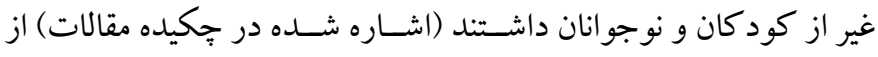
روند بررسى حذف شدند (צس مقاله) و تعداد YV مقاله براى بررسى تمام

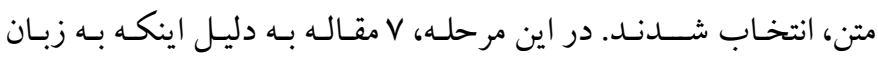

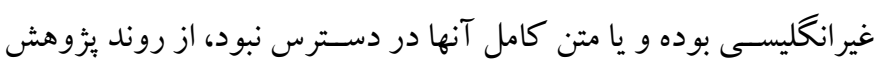

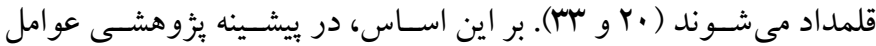

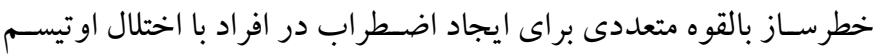

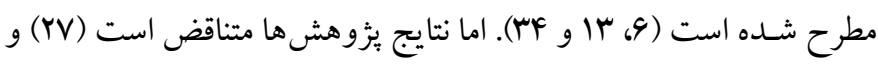

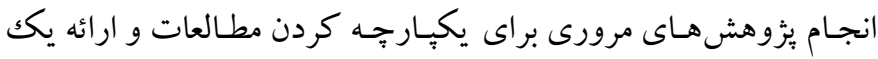

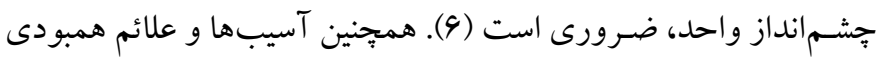
كه توســ اضـطر اب ايجاد مى شــوند، اهميت تشـخيص، درمان مؤثر

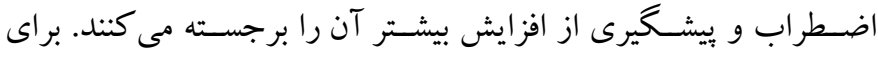
يشيـيرى از افزايش شـدت اضطر اب در كود كان و نوجوانان با اختاال

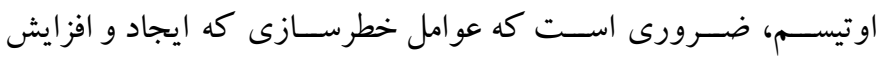

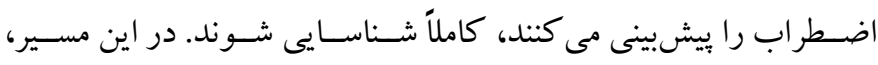
مى توان كود كان با اختلال اوتيسم كه براى ابتلاى به اضطر اب آسيب يذئير

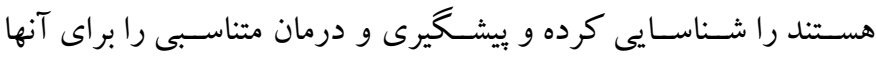

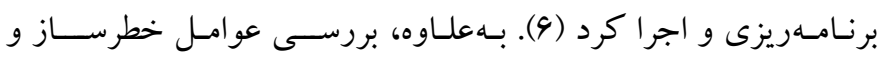

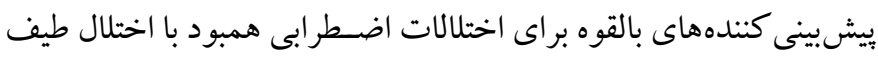

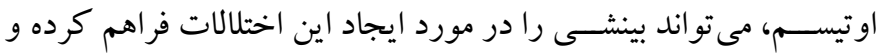
دقت تشخيصى در اختلال او تيسم را بهبود بخشند.

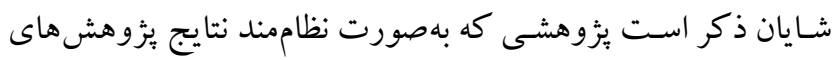
مختلف را در اين حيطه بررسى و عوامل خطرســاز اضـطراب در اختلال اوتيسم را به طور يكيارجه و جامع معرفى كند، انجام نشده است. همجنين

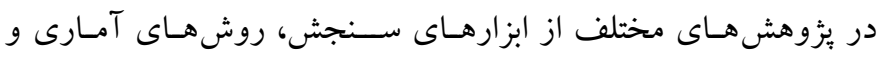

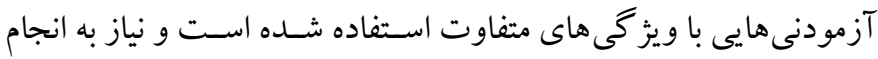

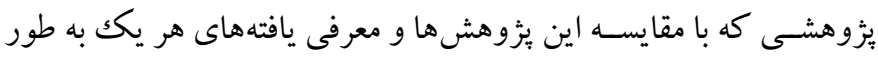

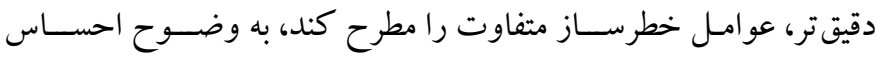
مىشـود. بدين تريتيب هدف از يزوهش حاضـر بررسى عوامل خطرسـاز

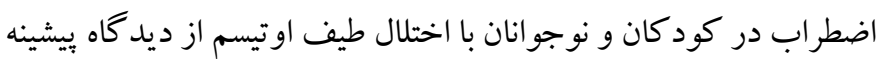

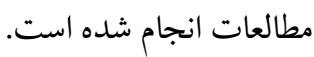
روش براى يرداختن به هدف اين يثوهش از روش مرورى نظام مند استفاده شد

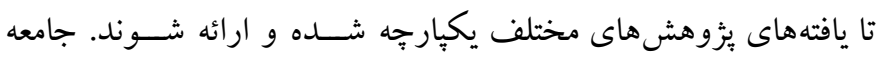

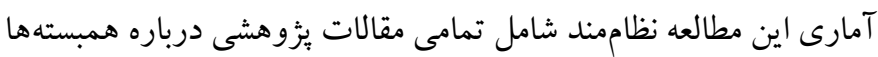

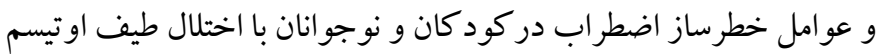


دكتر اى روانشناسى بودند، انجام شد و اكر اختلافنظرى وجود داشت با بحث و گفتو گو حل شد كه كدام مقاله باقى مانده و كدام مقاله حذف شوند. در مجموع ·r مقاله براى بررسى نهايى باقى ماندند.
حذف و در نهايت ·r مقاله وارد تحليل نهايى شــدند (شــكل I). براى اطمينان از كيفيت مقالات انتخاب شـده، تمام مراحل جسـتجو، غربالكرى و انتخاب نهايى مقالات، توسط دو يزوهشخر مستقل كه هر دو دانشجوى إمى

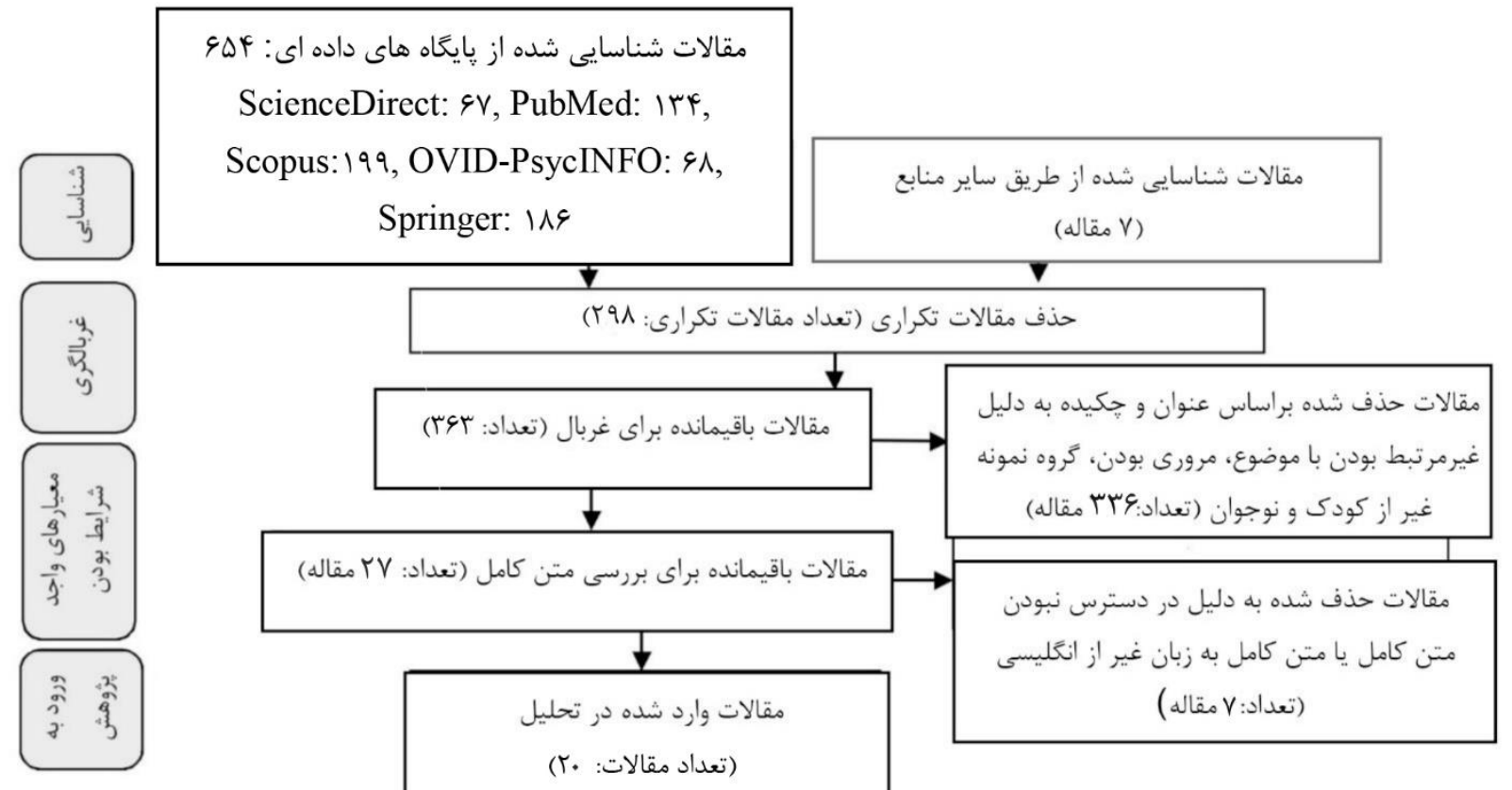

شكل ا: فلوخارت مراحل انتخاب و ورود مقالات به مطالعه مطابق با يروتكل يريزما

بررسى عواملى كه در اين •r مقاله ارائه شـده اسـت در ينج حيطه اصلى.

إفته ها

جنسـيت، ســن، شـــت علائم اوتيســم، كار كرد شــاختى، و مشـكلات بر اسـاس فلوجّارت بريزما، ·r مقاله انتخاب و وارد فرايند تحليل شــند. اجتماعى طبقهبندى شدند كه در بخش زير به آنها اشاره خواهد شد. اطلاعات مقالات منتخب و يافتهاى آنها در جدول ب ارائه شــده اسـت.

جدول r: مشخصات مقالات منتخب

\begin{tabular}{|c|c|c|c|c|}
\hline يافتهها & مقياس اندازه تيرى اضطراب & ويزكى هاى نمونه & سال & نويسند أن ان \\
\hline سن، هوش بهر، نقايص اجتماعى و شدت علائم اوتيسم نتو انست & مقياس آخنباخ (نسخه والد) & 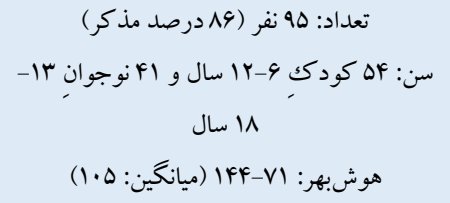 & $r \cdot 1 r$ & استرانگك و همكاران (q") \\
\hline شدت اوتيسم بهطور معكوس با اضطراب همبسته است. & 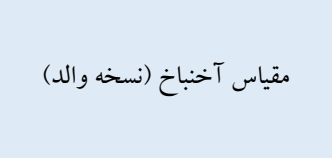 & 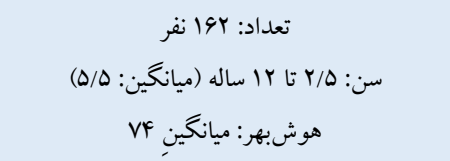 & $r+11$ & اسنو و لكاوالير (FV) \\
\hline شدت علائم اوتيسم از جمله بيش حساسيت حسى باعث تشديد & مقياس اضطر اب اسنيس (نسخه & 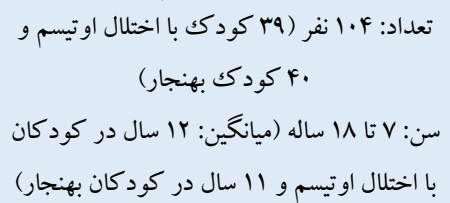 & $r \cdot I V$ & بلك و همكاران (\$4) \\
\hline
\end{tabular}




\begin{tabular}{|c|c|c|c|c|}
\hline & & 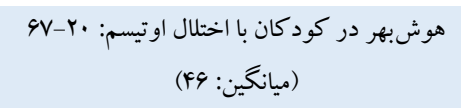 & & \\
\hline هرجه مهارتهاى ارتباطى دريافتى و بيانى بيشتر باشد، علائم & كوياس كود كان و نوزادان براى & 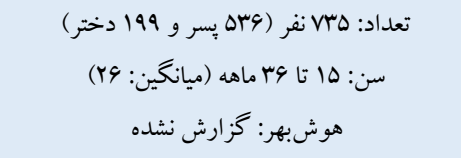 & $r \cdot I r$ & داويس و همكاران (•ه) \\
\hline سن، مشكلات اجتماعى و هوش بهطور مثبى اضطراب را ييشينى & مقياس آخنباخ (نسخه والد) & 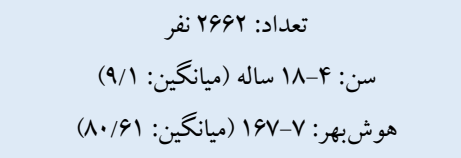 & $r \cdot 10$ & دوبين و همكاران (FF) \\
\hline اضطراب با شدت بيشتر علائم اوتيسم و سن بالاتر ارتباط داشت. & 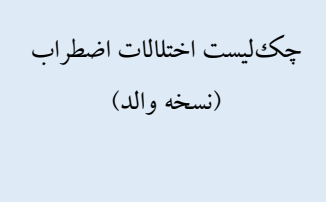 & 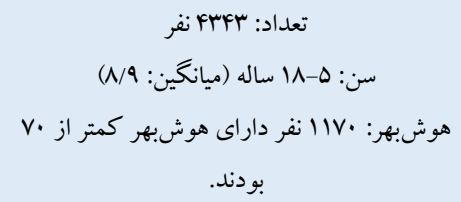 & $r .11$ & روزنبر گك و همكاران (N) \\
\hline 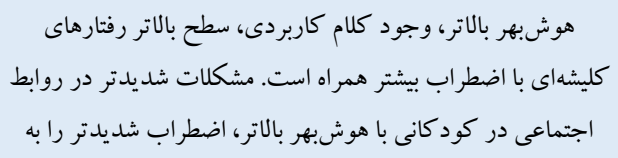 & $\begin{array}{c}\text { ير سشنامه علائم كودك و نوجوان } \\
\text { ونسخه والد) }\end{array}$ & 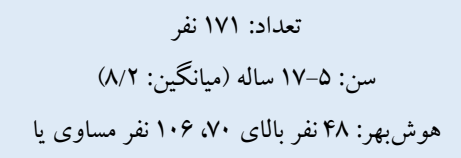 & $r \cdots \wedge$ & ساخو دولسكى و همكاران (•F) \\
\hline شدت اوتيسم، هوش.بهر و كار كرد انطباقى با اضطر اب همبسته & كود كق و ونوجوان ارزيابى روانيز شكى (نسخه والد) & 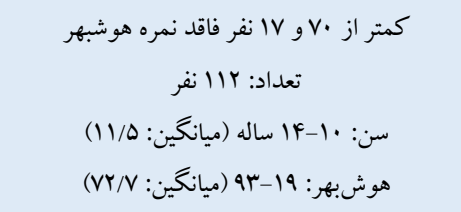 & $r \cdots \wedge$ & سيمونوف و همكاران (FF) إ) \\
\hline هر جه شدت علائم بيشتر باشد اضطراب كمتر است. & $\begin{array}{c}\text { يرسشنامه علائم مرضى كود كان } \\
\text { (نسخه والد) }\end{array}$ & 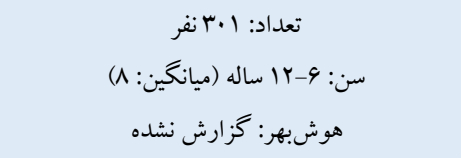 & $r \cdots \Delta$ & كادو و همكاران (FA) \\
\hline 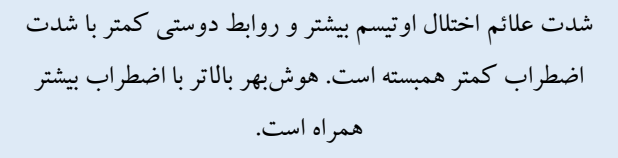 & 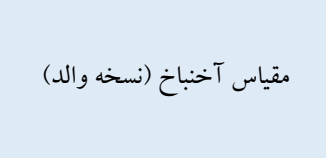 & 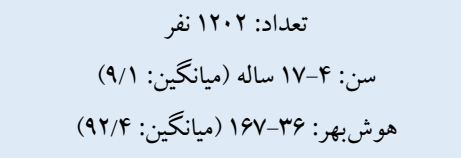 & $r \cdot 1$. & مازور كك و كانى (FI) \\
\hline سن، بهره هوشى و شدت علائم اوتيسم به طور مثبى اضطراب را & مقياس رفتارى كود كان (نسخه & 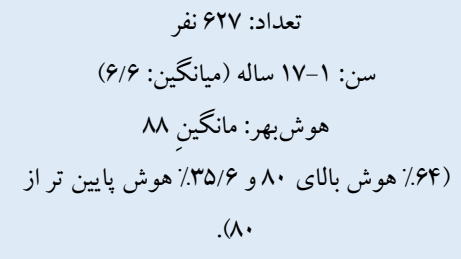 & $r .11$ & 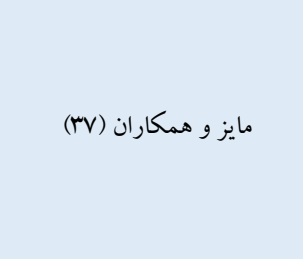 \\
\hline 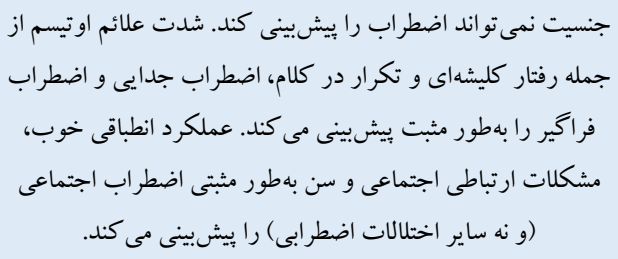 & مقياس اضطر اب اسينس (نسخه & 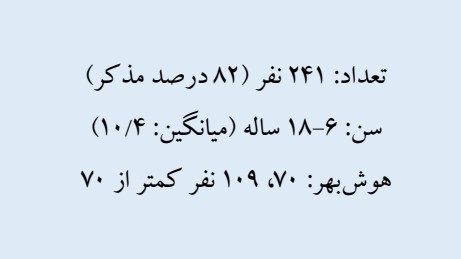 & $r \cdot 10$ & مخياتاى و همكاران (r4) \\
\hline كود كان دختر اضطراب بيشترى را نسبت به كود كان يسر تجربه & مقياس اضطر اب اسينس (نسخه & 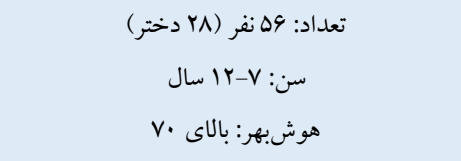 & $r \cdot l f$ & 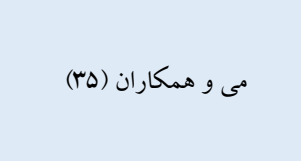 \\
\hline هوش بهر بهطور مثبت اضطراب را ييشبينى مى كند. & سيستم ارزيابى رفتارى براى كودان (نسخه والد) & 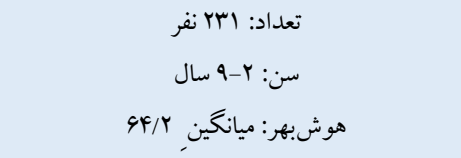 & $r \cdot I r$ & نيديتج و همكاران (Fr) \\
\hline سن بالاتر، هوش بيشتر و شدت علائم اوتيسم خفيفتر، اضطراب & مقياس آخنباخ (نسخه والد) & سن: تعداد: Y آسا نفر & $r .1 r$ & واسا و همكاران (rا) \\
\hline
\end{tabular}




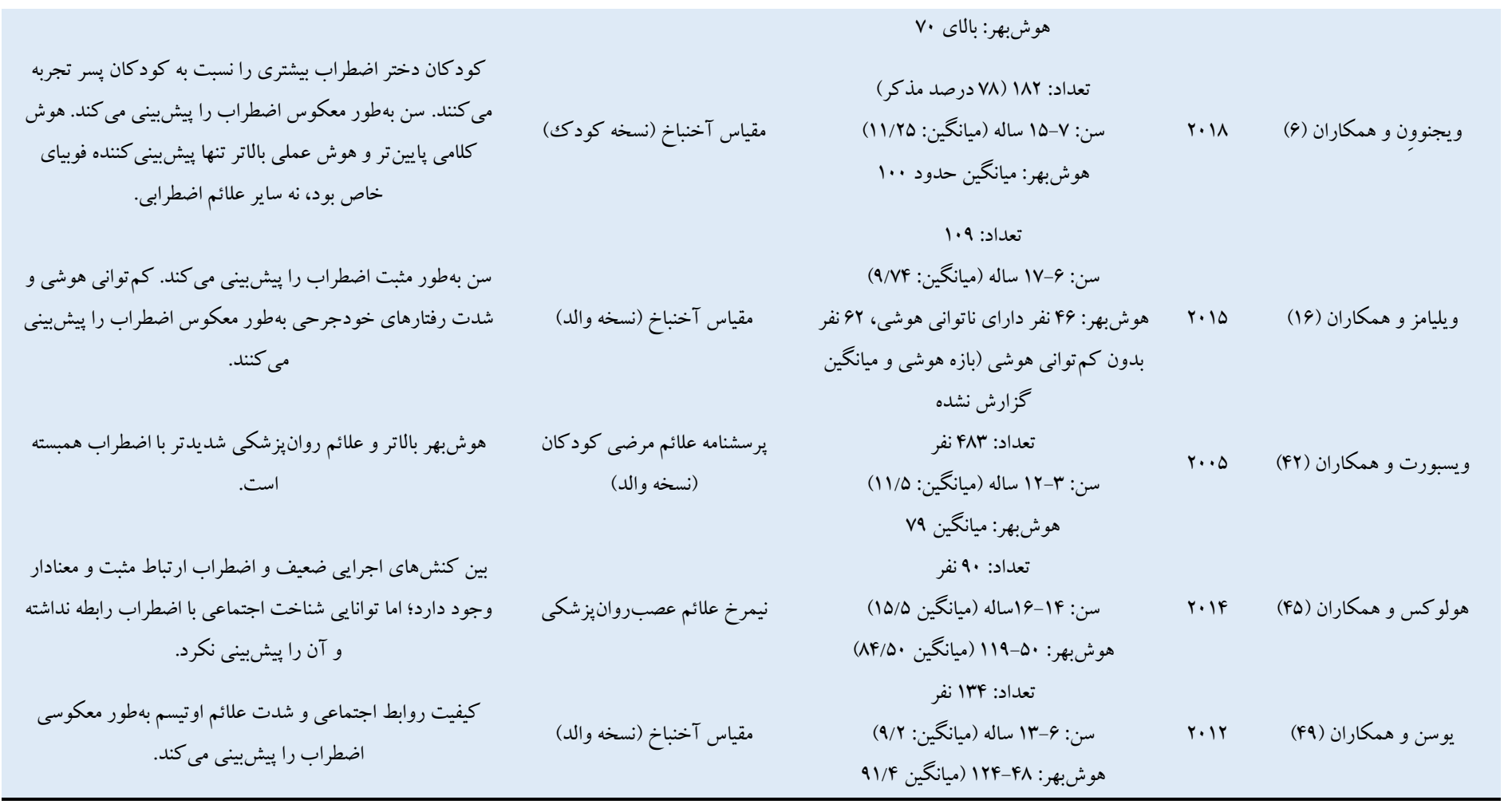

ارتبـاطى نـدارد (مـانند هو و ·F ). از بين مطالعات بررســىشــده در اين يثوهش، تنها يكك بثزوهش (9) مطرح كرد كه اضـطراب در بين كود كان با اختلال طيف اوتيسـم با سـن كمتر، شـيوع بيشـترى داشـته و سن ارتباط معكوسى با اضطر اب دارد.

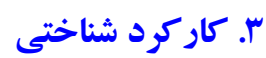
بر اســاس يزٔوهشهاى دوبين، ليبرمن -بتز و مايكلى ليز (YM)، مازوكك و

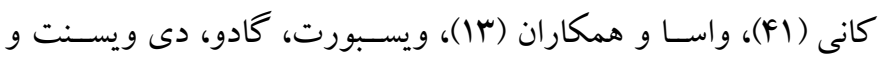
كومروى (FY)، و يليامز، ليدر، مانيون و جِن (19) و نيديتج، وارلا، كامبس و هيل (Fr) و مايز، كالهون، موراى و زاهيد (rV) اضـطر اب در كود كان با اختاال اوتيسـم با هوش بالاتر، شايعتر است و در نتيجه هوش يكك عامل خطرسـاز براى ابتلاى به اضـطر اب در كود كان و نوجوانان در نظر كرفته مىشـود. سـاخودولسـكى و همكاران (·F) نيز به اين نتيجه رسـيدند كه هوشبهر بالاتر و وجود كلام كاربردى، با اضطراب بيشـتر همراه اسـت و همجينين نارسـايى شـديدتر در روابط اجتماعى در كود كانى با هوشبهر بالاتر، اضـطراب شـديدتر را به همر اه دارد. البته هئوهشهاى سـينونوف، يّكلس، جارمن، جندلر، لو كاس و بايرد (FF) و اســتر انگك و همكاران (q)) رابطهاى بين هوش و سـطح اضـطراب در كود كان و نوجوانان با

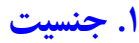

در بيشــتر يزوهش هايى كه در اين مطالعه بررسـى شـــند، تفاوتهاى جنسيتى در اضطراب زياد مورد توجه قرار نخرفته است و تنها دو مطالعه، جنسـيت دختر را به عنوان يكك عامل خطرسـاز ابتلاى به اضـطراب مطرح كردند (4و ها). يكك مطالعه نيز تفاوت جنسيتى را در ابتلاى به اضطراب مهم و يكك عامل خطرساز شناسايى نكرده است (وس). r. ســن تقويمى نيز به عنوان يكك عامل در رشــــ اضــطر اب در كود كان و نوجوانان با اختلال او تيسم در نظر گرفته شده است، اكر جه يافته ها در اين زمينه متناقض هسـتند. برخى مطالعات ســن را يكك عامل خطرسـاز براى ابتلاى به اضــطر اب در اين گروه دانســته و معتقداند ســن به طور مثبت اضـــر اب را در كودكـان و نوجوانان با اختلال طيف اوتيســم ييشبينى

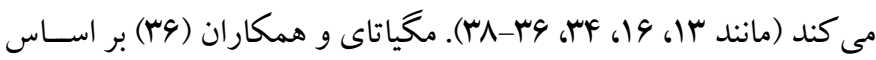
يثزوهش خود به اين نتيجه رســيدند كه ســن تنها ييشبينى كننده اختلال اضـطر اب اجتماعى و نه سـاير اختلالات اضطر ابى در كود كان و نوجوانان با اختلال طيف او تيسـم است. برخى ديخر از يثزوهش ها سن را يكك عامل خطر ندانسـته و كزارش كردهاند كه ســن به اضــطر اب در اين جمعيت 


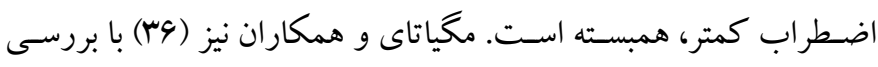

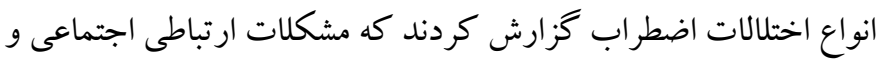

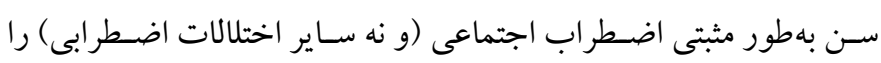

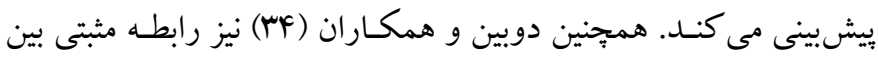

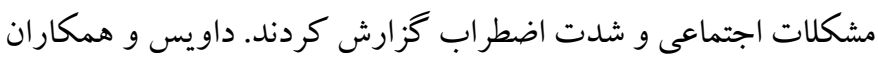

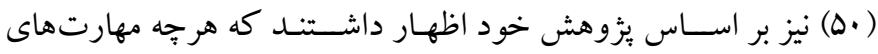
ارتباطى دريافتى و بيانى در كود كان با اختلال طيف اوتيسمم بيشـتر باشـد، علائم اضطر ابى بيشترى در اين كود كان مشاهده مى دودود.

\section{بحث و نتيجه كيرى}

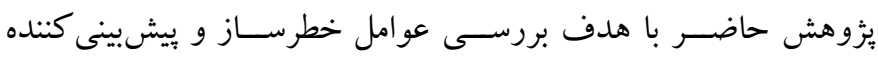

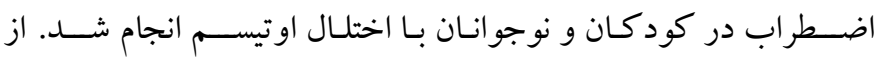
يُزوهش هاى بررسى شده در اين مطالعه ه عامل به عنوان عوامل خطر ساز و بيش يينى كننده اضطر اب مشخص شدند كه عبارتاند از: جنسيت، سن،

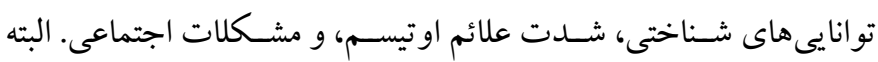
يافتهاى اين يثزوهش ها تا حدى متناقض بود.

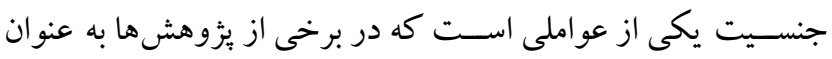

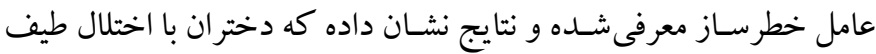

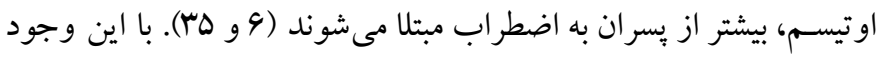

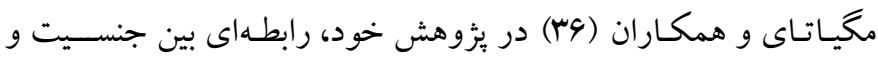

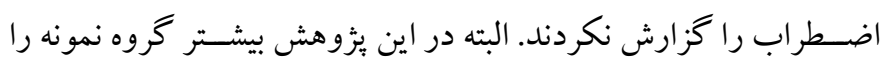

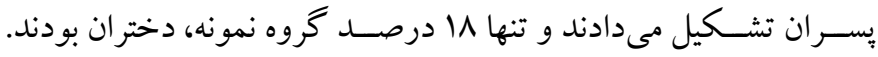

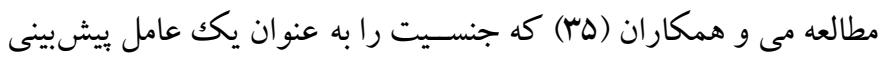
كننده اضطراب مورد بررسى قرار دادند، از تعداد برابر دختران و يسران

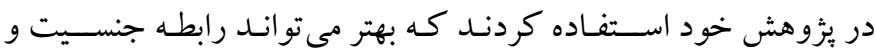

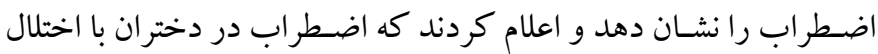
طيف او تيسـم بيشتر از بـران است. ويجنوون و همكاران (9) نيز يافته مى هـ

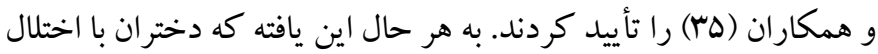

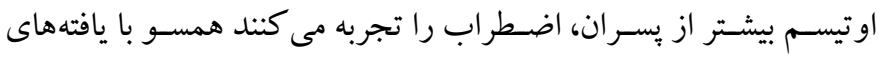
يزؤهشهايى اسـت كه تفاوتهاى جنسـيتى در اضـطر اب را در جمعيت

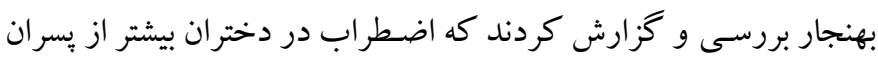
اسـت (YN). يكك تبيين براى اين تفاوت جنسـيتى اين اسـت كه والدين
اختلال طيف اوتيسـم نيافتند. از سـوى ديخر هولو كس و همكاران (FD) ارتباط اضطر اب و كنشهاى اجر ايى را در كود كان و نوجو انان با اختلال

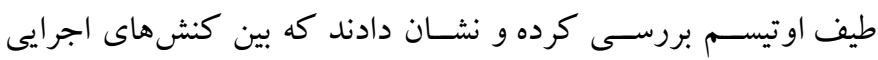
ضـعيف و اضـطراب ارتباط مثبت وجود دارد؛ اما شــناخت اجتماعى بـى ارتباطى با اضطر اب نداشته و آن را ييشبينى نكرد. ع. عدت علائم اوتيسم

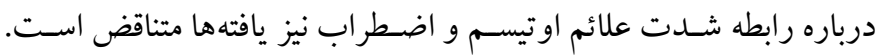
برخى يثزوهشـــران مطرح كردنـد كه كود كانى با شــــت علائم اختلال

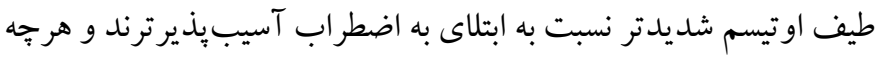

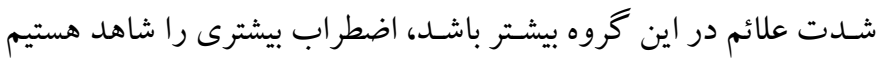

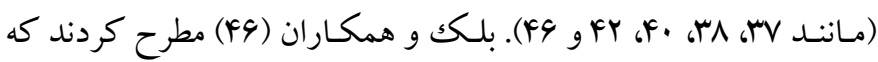
شـدت علائم اوتيسـم از جمله بيش حسـاسيتى حسى باعث تشـديد علائم

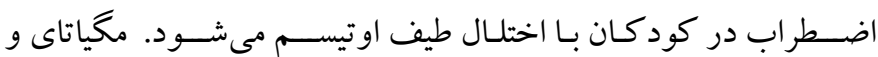

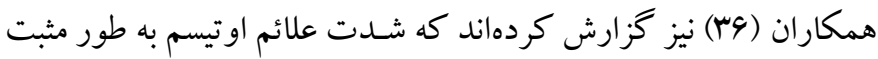
ييشينى كننده اضطر اب جدايى و فراخير (و نه اضطر اب اجتماعى) است.

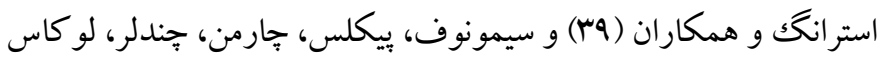
و بايرد (FF) نيز اعلام كردند كه شـدت علائم اوتيسـم نمى تواند اضطراب

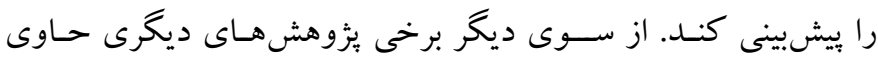

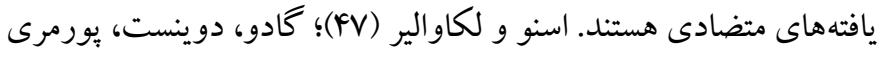

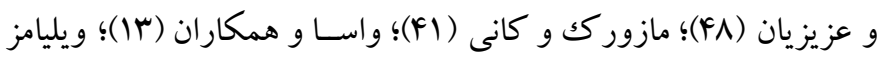

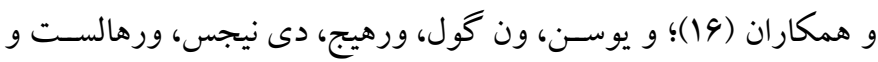

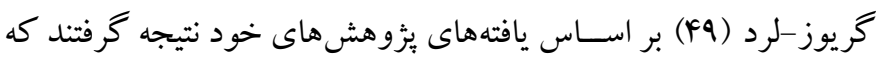
هرجه شـدت علائم اختلال بيشتر و در نتيجه او تيسم شديدتر باشد، احتمال

\section{ابتلاى به اضطر اب كمتر است.}

درباره ارتباط بين مشـكلات اجتماعى و اضـطراب، با وجود اينكه يكك مطالعه ارتباطى بين نارسايى اجتماعى و اضطر اب در كود كان و نوجوانان

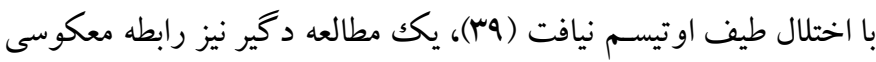

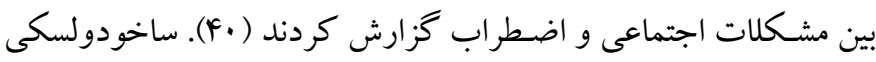

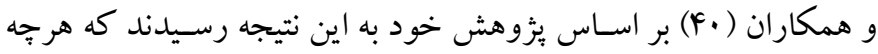

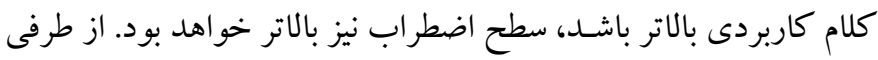

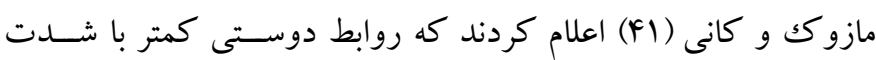


در تبيين شيوع بيشتر اضطر اب در كود كان و نوجوانانى با سن بالاتر و

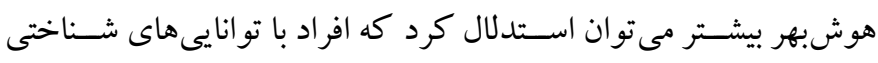
بالاتر، آكاهى بيشـترى از نقايص اجتماعى و انطباقى خود دارند و همين

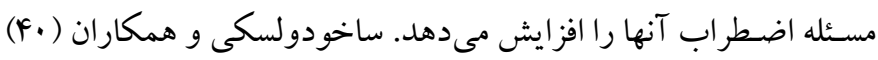
نيز بـه اين نتيجه رسـيــند كه نقص شـــيدتر در روابط اجتماعى در

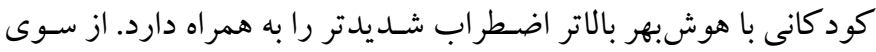

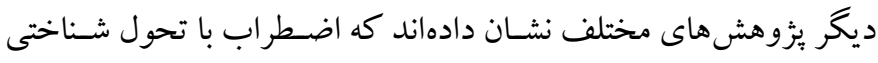

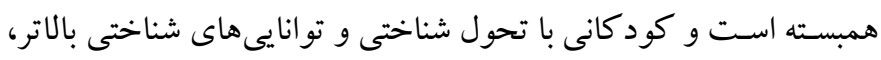

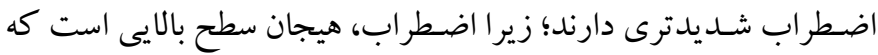

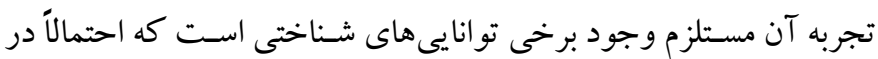

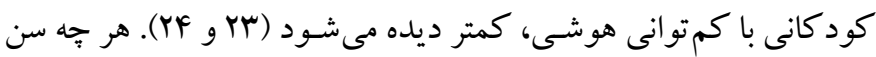
افزايش مى يابد، توانايىهاى شناختى نيز تحول بيشترى بيدا مى كنند و در

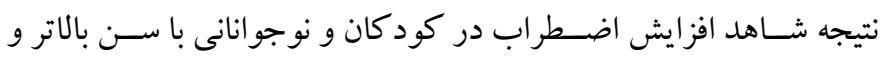

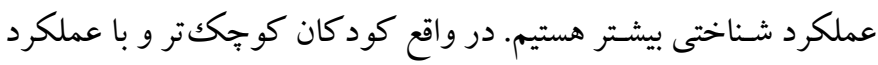

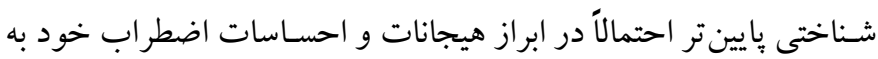

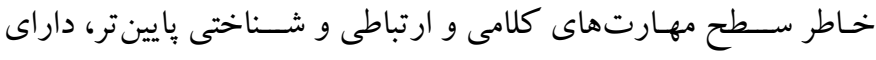

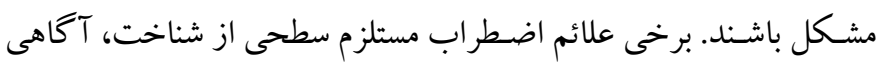

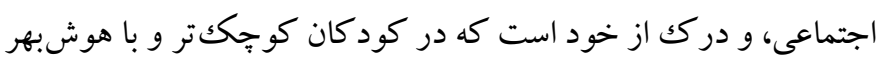

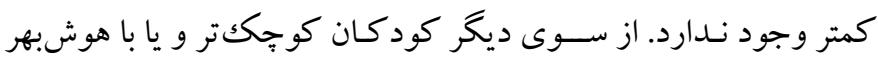

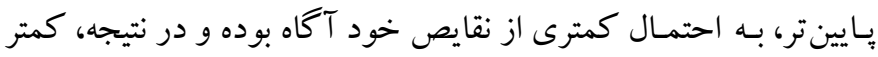
دجار اضطراب ناشى از آن مىشوند (YV).

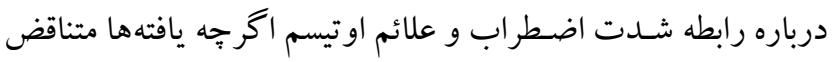

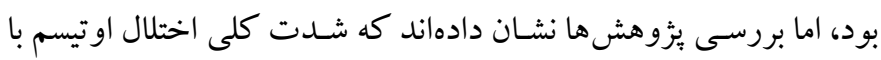
علائم اضطر اب ارتباط معكوس دارد و هر جه شدت كلى اوتيسم هايينتر

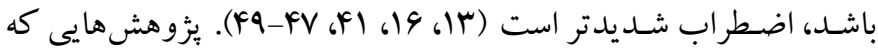
نتيجه متضادى را گزارش كرده و اعلام كردند كه علائم اوتيسم شديدتر،

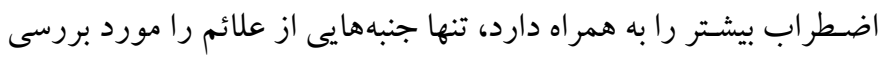

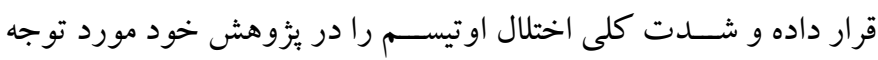

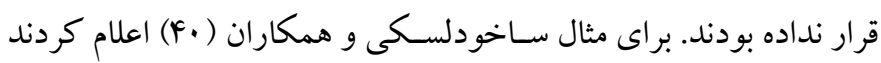

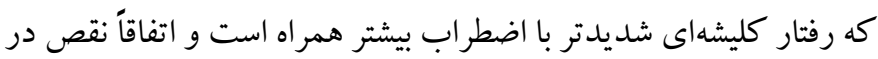

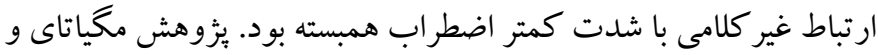

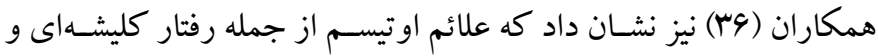

كرايش دارند اضطراب را بيشتر در دختران گزارش كنند تا بـران، و در

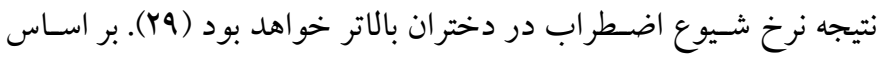

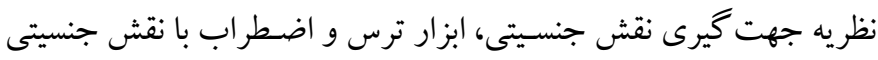

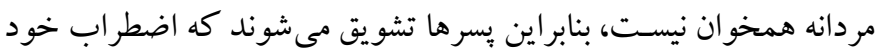
را سر كوب و آن را مديريت كنند. برعكس، نقش جنسيتى زنانه، دختران را تشـويق مى كند تا بريشـانى و اضطر اب خود را رانشـان دهند تا حمايت

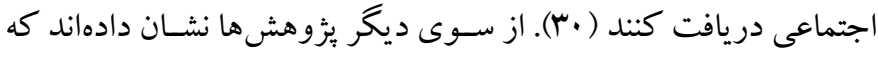

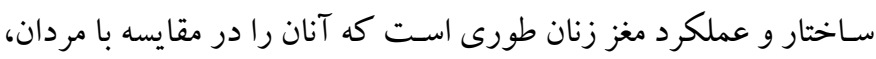
نسبت به اضطر اب آسيب بذيرتر مى كند ( آس).

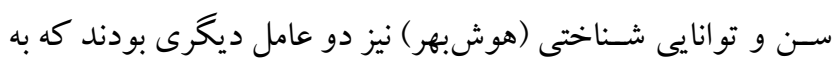

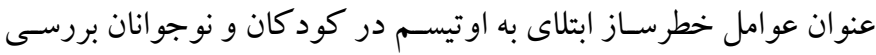

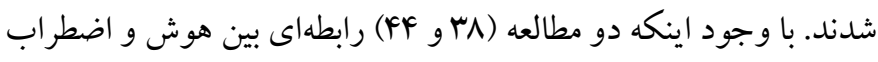

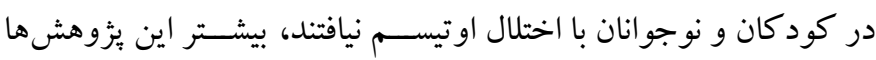
هوش را به عنوان يكك عامل خطرساز براى ابتلا به اضطر اب معرفى كردند

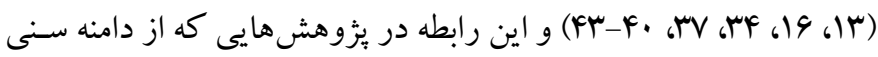
متفـاوتى از كود كـان و از مقيـاسهاى متفاوتى براى اندازهگيرى هوش و و

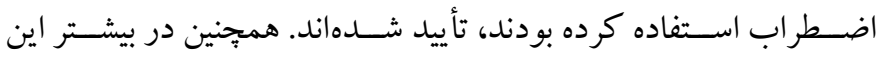

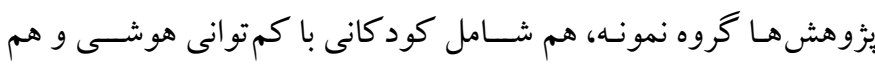

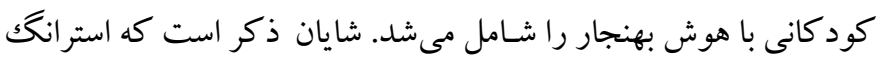

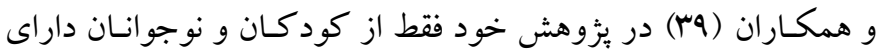

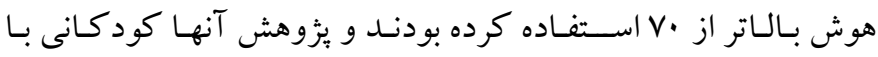

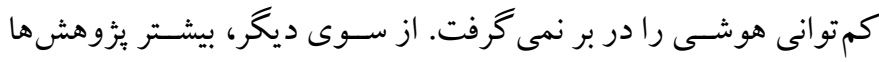

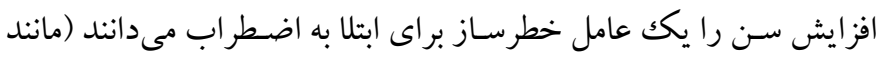

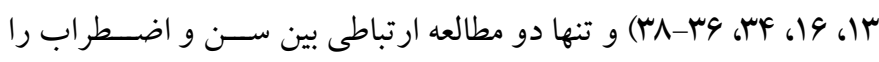

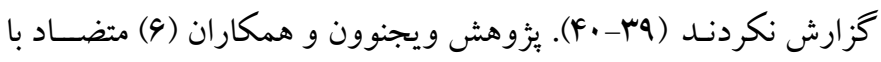

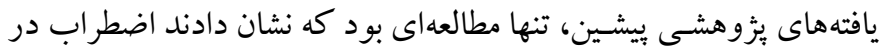

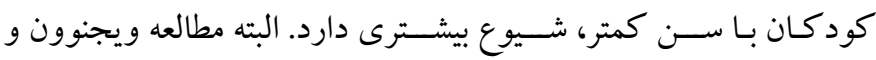

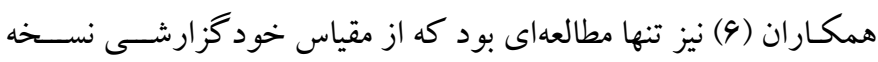
كود كك براى سـنجش اضـطراب اسـتفاده كرده بود؛ در حالى كه سـاير

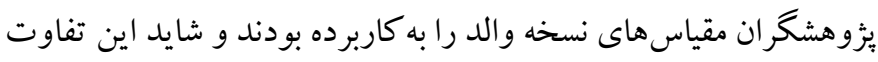
در ابزار بتواند اين يافته متضاد را تا حدى توجيه كند. 
اختلال طيف اوتيسـم نيافت (9)، مطالعهاى ديخر رابطه معكوسـى بين

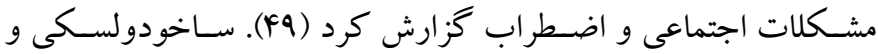

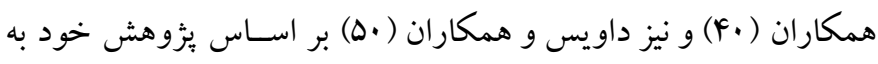
اين نتيجه رسيدند كه هرجه كلام كاربردى بالاتر باشد، سطح اضطراب نيز

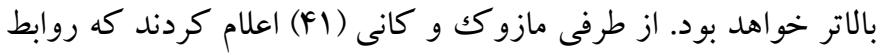
دوستى كمتر با شدت اضطراب كمتر، همبسته است. مخياتاى و همكاران

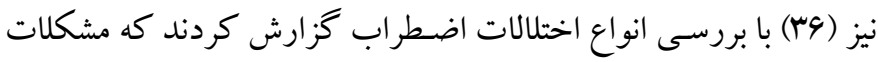
ارتباط اجتماعى و ســن به طور مثبتى اضــر اب اجتماعى (و نه ســاير

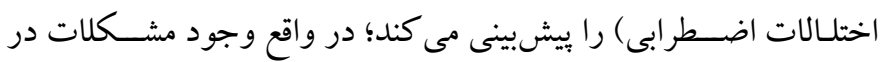
روابط اجتمـاعى و كمبود مهـارتهـاى اجتمـاعى در برقرارى رابطهـ بـا

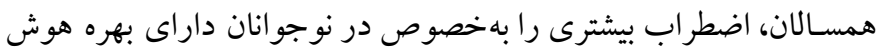

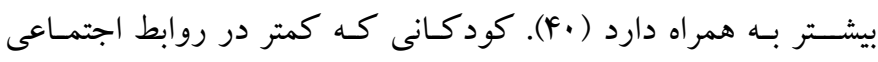

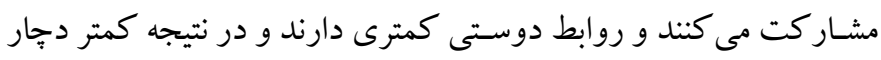

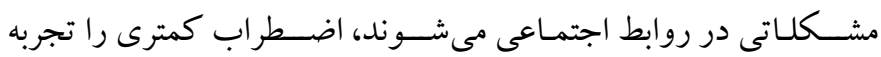

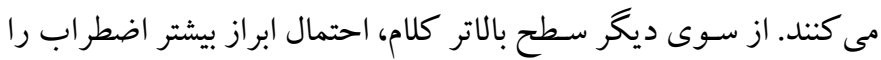

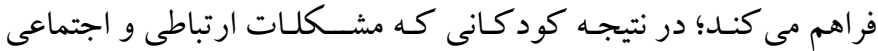

كمترى دارند، بيشتر علائم خود را بروز داده و گزارش مى كنند ( •.F).

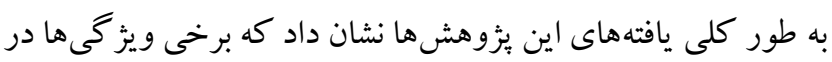

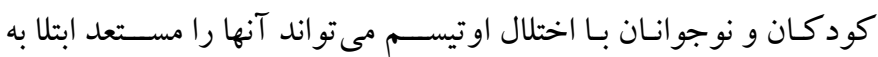

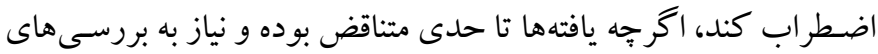

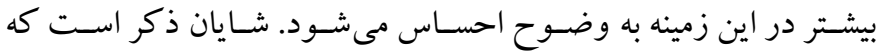

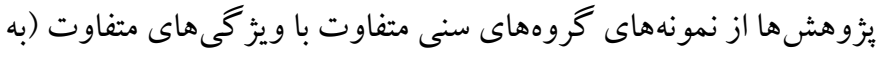

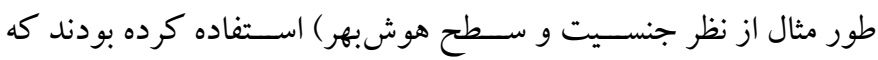

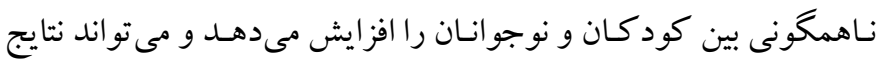
متفاوتى نيز به بار آورد. همجنين ابزارهاى متفاوتى براى سنجش اضطراب

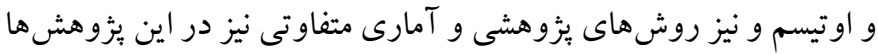

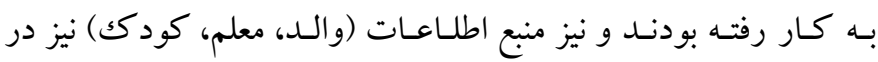

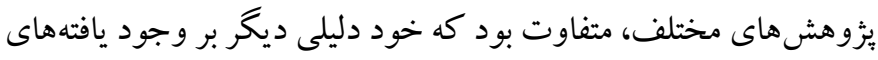
متناقض است. مطالعات انجام شـده درباره عوامل خطرسـاز اضطراب در كود كان با اختلال اوتيسم در ييشينه يزوهش، هر يكك بر برخى از عوامل تأكيد كرده
تكرار در كلام با اضـطراب جدايى و اضـطراب فراخير (و نه اضـطراب

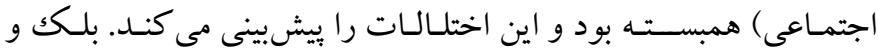

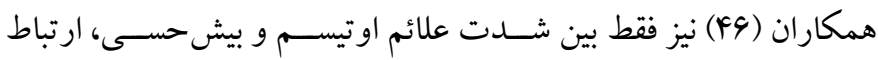

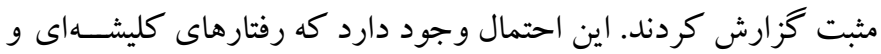
بيشحسـاسـيت حسى كود كك از جانب مادر كه شـــت اضـطر اب را

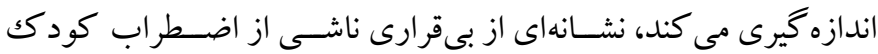
قلمداد شده و در نتيجه هرجه اين رفتارها در كود كك شديدتر باشد، سطح

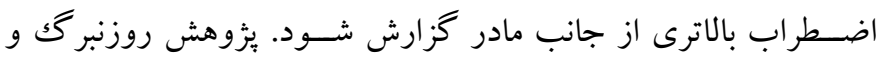

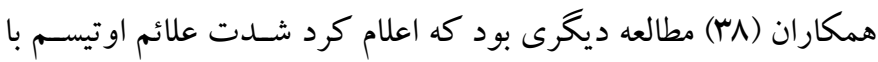

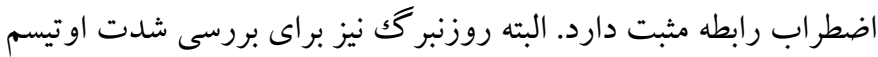
بر نقايص اجتماعى و نه شـــت كلى علائم تمركز كرده و از مقياس

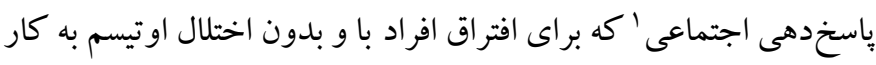

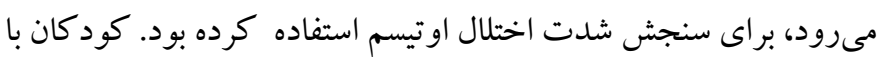

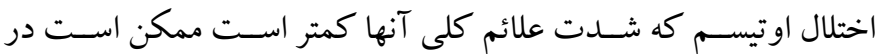
شـرايط اجتماعى كشـاكشبر انخيز ترى قرار بخيرند زيرا دركك بيشترى از از شـ ايط خود دارند كه در نتيجه سطح اضطراب را افزايش مىدهد (Y9).

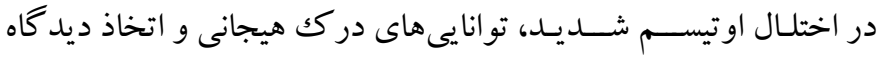

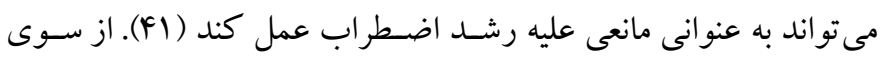

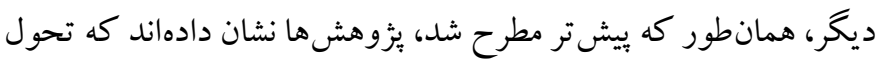
شناختى در ابتلاى به اضطر اب نقش دارد و رابطه مثبى بين تحول شناختى و ابتلاى به اضطراب گز ارش شده است. همجنين يُروهش ها حاكى از آن

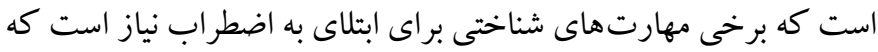

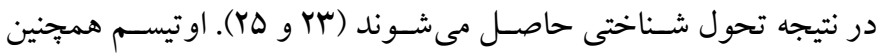

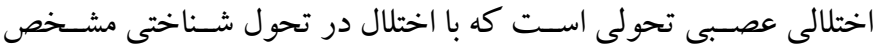

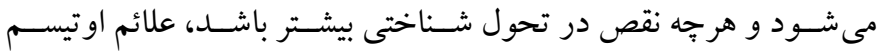

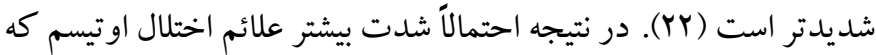
با نقص شناختى بيشتر همراه است، مانع تحول برخى توانايى هاى شناختى

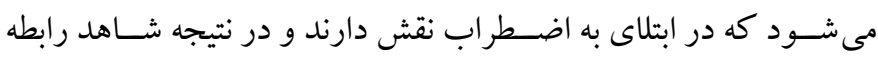
معكوس بين شدت علائم اختلال اوتيسم و ابتلاى به اضطر اب هستيم. درباره ارتباط بين مشكلات اجتماعى و اضطراب، با وجود اينكه يك سيك مطالعه، ارتباطى بين نقص اجتماعى و اضطراب در كودكان و نوجو انان با 
است تا تشخيص اضطراب در اين كود كان با احتياط بيشترى انجام شود. از ســوى ديكر، بـا تو جه به اينكه هوشبهر و توانايى هاى شــناختى يك بك عامل خطرســاز براى ابتلا به اضـطر اب در اختلال اوتيســـم اســـ، انجام يثزوهشهـايى كه توانايىهاى شــناختى دخيل در ابتلاى به اضــطراب را مشـخص كرده و در كود كان مبتلا به اختلال او تيسـم مورد سـنجش قرار دهند، مى تواند در بثزوهشهاى آتى مورد توجه قرار گيرد.

دسترسى محدود به برخى يايخاههاى اطلاعاتى از جمله PsycINFO ،

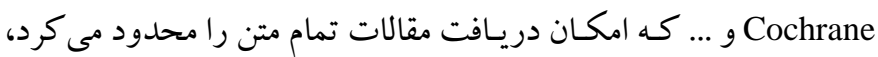
باعث شـد كه مطالعه حاضـر تنها در سـه يايكاه دادهاى انجام شـود كه از محدوديت هاى بثزوهش حاضر است.

ملاحظات اخلاقى ييروى از اصــول اخلاق يثوهش: اين مقاله بركرفته از رسـاله دوره دكتراى تخصصى نويسـنده نخست كه به تأييد كميته اخلاق دانشگاه شهيد بهشتى با كد اخلاق IR.SBU.REC.1398.023 حامى مالى: اين مطالعه بدون حمايت مالى هيج مؤسسه و سازمانى انجام شده است. نقش هر يكى از نويسـند كان: نويسـنده نخست، مجرى اصلى يُزوهش بوده است و

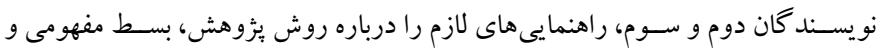
فرايند يُزوهش ارائه كردهاند.

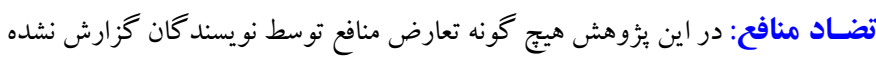
است. تشـكر و قدردانى: بدين وسـيله از تمامى افرادى كه سـهمى در اجراى اين يثوهش داشتند، قدردانى مى شود.
و جنــد عامل را مورد بررسـى قرار داده بودند. مطالعه حاضــر يافتههاى

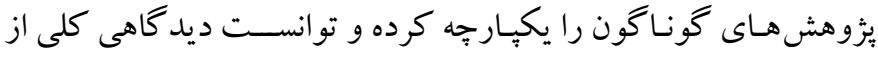
عوامـل خطرســاز اضــطراب در اوتيســم ارائسه دهـــ. مرورى جـامع بر

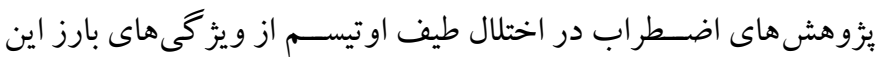

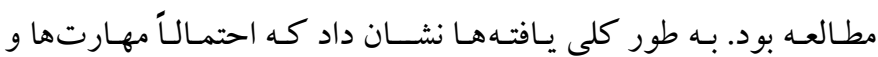
ويز كى هاى شناختى كود كان با اختلال اوتيسم در ابتلاى به اضطر اب نقش دارد. با افزايش سـن و رشــد بيشـتر شـناخت در اين كود كان، اضـطر اب افزايش مىيابد. در نتيجه لازم است كه مفهوم يردازى جامعى از اضطراب در اختلال طيف اوتيسـم بر اسـاس ويز كى ها و نيمرخ شـناختى آنها انجام شـــود. ارائه يكك مفهو ميردازى با تو جه به ويز گیى هاى كود كان با اختلال او تيسـم و نقايص شـناختى آنها مى تواند در كنار يافتهاى اين يثزوهش به دركى بهتر از يديده اضطراب در اين اختلال منجر شود. بيشـنهاد مى شـود كه يثزوهش هاى بيشتر با حجم نمونه هاى بالاتر و نيز گروه نمونههاى همكن تر براى بررسى ساير عوامل خطرساز اضطراب در اختلال اوتيسـم انجام شـود تا به وضوح بيشترى بتوان عوامل خطرساز ابتلا رادر اين جمعيت مشــحص كرد. همجينين احتمالاً ماهيت اضــطر اب در كود كان و نوجو انان با اختلال او تيسمم با كود كان بهنجار متفاوت اسـت و در نتيجه نياز به سـاخت ابزارهاى دقيق سنجش اضطراب در اين كود كان و نوجوانان احسـاس مىشـود تا روند تشـخيص دقيق تر انجام شـود؛ زيرا علائم اضـطر اب هميوشـانى زيادى با علائم اوتيسم دارد (1) و ضسرورى 


\section{References}

1. Sadock BJ, Sadock VA, Ruiz P. Kaplan \& Sadock's comprehensive textbook of psychiatry. Philadelphia, PA: Lippincott Williams \& Wilkins; 2017. 127 p. [Link]

2. Salazar F, Baird G, Chandler S, Tseng E, O'sullivan T, Howlin P, et al. Co-occurring Psychiatric Disorders in Preschool and Elementary School-Aged Children with Autism Spectrum Disorder. J Autism Dev Disord.. 2015;45(8):2283-94. DOI: 10.1007/s10803015-2361-5 [Link]

3. White SW, Oswald D, Ollendick T, Scahill L. Anxiety in children and adolescents with autism spectrum disorders. Clin Psychol Rev. 2009;29(3):216-29. DOI: 10.1016/j.cpr.2009.01.003 [Link]

4. De Bruin EI, Ferdinand RF, Meester S, de Nijs PFA, Verheij F. High Rates of Psychiatric Co-Morbidity in PDD-NOS. J Autism Dev Disord.. 2007;37(5):87786. DOI: 10.1007/s10803-006-0215-x [Link]

5. Van Steensel FJA, Bögels SM, Perrin S. Anxiety Disorders in Children and Adolescents with Autistic Spectrum Disorders: A Meta-Analysis. Clin Child Fam Psychol Rev. 2011;14(3):302-17. DOI:10.1007/ s10567-011-0097-0 [Link]

6. Wijnhoven LAMW, Creemers DHM, Vermulst AA, Granic I. Prevalence and Risk Factors of Anxiety in a Clinical Dutch Sample of Children with an Autism Spectrum Disorder. Front psychiatry. 2018;9(50):110. DOI: $10.3389 /$ fpsyt.2018.00050 [Link]

7. Adams D, Clark M, Simpson K. The Relationship Between Child Anxiety and the Quality of Life of Children, and Parents of Children, on the Autism Spectrum. J Autism Dev Disord. 2019;9:1-14. DOI: 10.1007/s10803-019-03932-2. [Link]

8. Canitano R. Self injurious behavior in autism: clinical aspects and treatment with risperidone. J Neural Transm. 2006;113(3):425-31. DOI: 10.1007/s00702005-0337-x [Link]

9. Mazurek MO, Vasa RA, Kalb LG, Kanne SM, Rosenberg D, Keefer A, et al. Anxiety, Sensory OverResponsivity, and Gastrointestinal Problems in Children with Autism Spectrum Disorders. J Abnorm Child Psychol.. 2013;41(1):165-76. DOI: 10.1007/ s10802-012-9668-x.[Link]

10. Rzepecka H, McKenzie K, McClure I, Murphy S. Sleep, anxiety and challenging behaviour in children with intellectual disability and/or autism spectrum disorder. Res Dev Disabil. 2011;32(6):2758-66. DOI: 10.1016/j.ridd.2011.05.034 [Link]

11. Drahota A, Wood JJ, Sze KM, Van Dyke M. Effects of cognitive behavioral therapy on daily living skills in children with high-functioning autism and concurrent anxiety disorders. J Autism Dev Disord. 2011;41(3):257-65. DOI: 10.1007/s10803-010-10374 [Link]

12. Hallett V, Lecavalier L, Sukhodolsky DG, Cipriano N, Aman MG, McCracken JT, et al. Exploring the manifestations of anxiety in children with autism spectrum disorders. J Autism Dev Disord. 2013; 43(10): 2341-2352. DOI: 10.1007/s10803-013-17751. [Link]

13. Vasa RA, Kalb L, Mazurek M, Kanne S, Freedman B, Keefer A, et al. Age-related differences in the prevalence and correlates of anxiety in youth with autism spectrum disorders. Res Autism Spectr Disord. 2013; 7(11): 1358-1369. DOI: 10.1016/j.rasd.2013.07 .005 [Link]

14. MacNeil BM, Lopes VA, Minnes PM. Anxiety in children and adolescents with autism spectrum disorders. Res Autism Spectr Disord. 2009; 39(1): 121. DOI: 10.1016/j.cpr.2009.01.003 [Link]

15. Tsai L. Diagnosis and treatment of anxiety disorders in individuals with autism spectrum disorder. In: Baron MG, Groden J, Groden G, Lipsitt LP, editors. Stress and coping in autism. Oxford University Press; 2006, pp: 388-440. [Link]

16. Williams S, Leader G, Mannion A, Chen J. An investigation of anxiety in children and adolescents with autism spectrum disorder. Res Autism Spectr Disord. 2015; 10: 30-40. DOI: 10.1016/j.rasd.2014. 10.017 [Link]

17. Kerns CM, Renno P, Kendall PC, Wood JJ, Storch EA. Anxiety disorders interview schedule-autism addendum: reliability and validity in children with autism spectrum disorder. J Clin Child Adolesc Psychol. 2017; 46(1): 88-100. DOI: 10.1080/ 15374416.2016.1233501 [Link]

18. Van Steensel FJA, Bögels SM, Wood JJ. Autism spectrum traits in children with anxiety disorders. J Autism Dev Disord. 2013; 43(2): 361-370. DOI: 10.1007/s10803-012-1575-z [Link]

19. Canitano R. Self injurious behavior in autism: clinical aspects and treatment with risperidone. $\mathrm{J}$ Neural Transm (Vienna). 2006; 113(3): 425-431. DOI: 10.1007/s00702-005-0337-x [Link]

20. Adams D, Young K, Keen D. Anxiety in Children with Autism at School: a Systematic Review. Rev J Autism Dev Disord. 2019;1-15. DOI: 10.1007/s40489 -019-00172-z [Link]

21. Lecavalier L, Wood JJ, Halladay AK, Jones NE, Aman MG, Cook EH, et al. Measuring Anxiety as a 
Treatment Endpoint in Youth with Autism Spectrum Disorder. J Autism Dev Disord. 2014;44(5):1128-43. DOI: 10.1007/s10803-013-1974-9 [Link]

22. American Psychiatric Association. Diagnostic and Statistical Manual of Mental Disorders. Washington: American Psychiatric Association. 2013. [Link]

23. Broeren S, Muris P. The Relation Between Cognitive Development and Anxiety Phenomena in Children. J Child Fam Stud. 2009;18(6):702-9. DOI: 10.1007/ s10826-009-9276-8 [Link]

24. Muris P, Merckelbach H, Luijten M. The connection between cognitive development and specific fears and worries in normal children and children with belowaverage intellectual abilities: a preliminary study. Behav Res Ther. 2002;40(1):37-56. DOI: 10.1016/S0005-7967(00)00115-7 [Link]

25. Vancu G. Anxiety of children with intelectual disability. Agora Psycho-Pragmatica. 2018;12(1):107 -14 . [Link]

26. Pearson DA, Loveland KA, Lachar D, Lane DM, Reddoch SL, Mansour R, et al. A Comparison of Behavioral and Emotional Functioning in Children and Adolescents with Autistic Disorder and PDDNOS. Child Neuropsychol. 2006; 12(4-5): 321-333. DOI: 10.1080/09297040600646847 [Link]

27. Kerns CM, Kendall PC. The Presentation and Classification of Anxiety in Autism Spectrum Disorder. Clin Psychol Sci Pract. 2012;19(4):323-47. DOI: $10.1111 /$ cpsp. 12009 [Link]

28. Christiansen DM. Examining Sex and Gender Differences in Anxiety Disorders. In: Durbano F, editor. A Fresh Look at Anxiety Disorders. InTech; 2015 [Link]

29. McLean CP, Anderson ER. Brave men and timid women? A review of the gender differences in fear and anxiety. Clin Psychol Rev. 2009; 29(6): 496-505. DOI: 10.1016/j.cpr.2009.05.003 [Link]

30. Zalta AK, Chambless DL. Understanding Gender Differences in Anxiety. Psychol Women Q. 2012;36(4): 488-99. DOI:10.1177/036168431245 0 004 [Link]

31. Raznahan A, Shaw PW, Lerch JP, Clasen LS, Greenstein D, Berman R, et al. Longitudinal fourdimensional mapping of subcortical anatomy in human development. Proc Natl Acad Sci. 2014;111(4):1592-7. DOI: 10.1073/pnas.1316911111 [Link]

32. Kerns CM, Kendall PC. Autism and Anxiety: Overlap, Similarities, and Differences. 2014; p. 7589. DOI: 10.1007/978-3-319-06796-4_6 [Link]

33. Smith IC, Ollendick TH, White SW. Anxiety moderates the influence of ASD severity on quality of life in adults with ASD. Res Autism Spectr Disord.. 2019;62:39-47. DOI: 10.1016/J.RASD.2019.03.001 [Link]

34. Dubin AH, Lieberman-Betz R, Michele Lease A. Investigation of individual factors associated with anxiety in youth with autism spectrum disorders. J Autism Dev Disord. 2015; 45(9): 2947-2960. DOI: 10.1007/s10803-015-2458-x [Link]

35. May T, Cornish K, Rinehart N. Does gender matter? A one year follow-up of autistic, attention and anxiety symptoms in high-functioning children with autism spectrum disorder. J Autism Dev Disord. 2014; 44(5): 1077-1086. DOI: 10.1007/s10803-013-1964-y [Link]

36. Magiati I, Ong C, Lim XY, Tan JW-L, Ong AYL, Patrycia F, et al. Anxiety symptoms in young people with autism spectrum disorder attending special schools: Associations with gender, adaptive functioning and autism symptomatology. Autism. 2016; 20(3): 306-320. DOI: 10.1177/1362361315577 519 [Link]

37. Mayes SD, Calhoun SL, Murray MJ, Zahid J. Variables associated with anxiety and depression in children with autism. J Dev Phys Disabil. 2011; 23(4): 325-337.DOI: 10.1007/s10882-011-9231-7 [Link]

38. Rosenberg RE, Kaufmann WE, Law JK, Law PA. Parent report of community psychiatric comorbid diagnoses in autism spectrum disorders. Autism Res Treat. 2011; ID 405849: 1-10. DOI: 10.1155/2011/ 405849 [Link]

39. Strang JF, Kenworthy L, Daniolos P, Case L, Wills MC, Martin A, et al. Depression and anxiety symptoms in children and adolescents with autism spectrum disorders without intellectual disability. Res Autism Spectr Disord. 2012; 6(1): 406-412. DOI:10.1016/j.rasd.2011.06.015 [Link]

40. Sukhodolsky DG, Scahill L, Gadow KD, Arnold LE, Aman MG, McDougle CJ, et al. Parent-Rated anxiety symptoms in children with pervasive developmental disorders: frequency and association with core autism symptoms and cognitive functioning. J Abnorm Child Psychol. 2008; 36(1): 117-128. DOI:10.1007/s10802007-9165-9 [Link]

41. Mazurek MO, Kanne SM. Friendship and internalizing symptoms among children and adolescents with ASD. J Autism Dev Disord. 2010; 40(12): 1512-1520. DOI: 10.1007/s10803-010-1014y. [Link]

42. Weisbrot DM, Gadow KD, DeVincent CJ, Pomeroy 
J. The presentation of anxiety in children with pervasive developmental disorders. J Child Adolesc Psychopharmacol. 2005; 15(3): 477-496. DOI: 10.10 89/cap.2005.15.477 [Link]

43. Niditch LA, Varela RE, Kamps JL, Hill T. Exploring the association between cognitive functioning and anxiety in children with autism spectrum disorders: the role of social understanding and aggression. J Clin Child Adolesc Psychol. 2012; 41(2): 127-137. DOI: 10.1080/15374416.2012.651994 [Link]

44. Simonoff E, Pickles A, Charman T, Chandler S, Loucas T, Baird G. Psychiatric disorders in children with autism spectrum disorders: Prevalence, comorbidity, and associated factors in a populationderived sample. J Am Acad Child Adolesc Psychiatry. 2008; 47(8): 921-929. DOI: 10.1097/CHI.0b013e 318179964f [Link]

45. Hollocks MJ, Jones CRG, Pickles A, Baird G, Happé $\mathrm{F}$, Charman $\mathrm{T}$, et al. The association between social cognition and executive functioning and symptoms of anxiety and depression in adolescents with autism spectrum disorders. Autism Res. 2014; 7(2): 216-228. DOI: 10.1002/aur.1361 [Link]

46. Black KR, Stevenson RA, Segers M, Ncube BL, Sun SZ, Philipp-Muller A, et al. Linking Anxiety and Insistence on Sameness in Autistic Children: The Role of Sensory Hypersensitivity. J Autism Dev Disord..
2017;47(8):2459-70. DOI: 1007/s10803-017-3161-x [Link]

47. Snow AV, Lecavalier L. Comparing autism, PDDNOS, and other developmental disabilities on parentreported behavior problems: little evidence for ASD subtype validity. J Autism Dev Disord. 2011; 41(3): 302-310. DOI:10.1007/s10803-010-1054-3 [Link]

48. Gadow KD, Devincent CJ, Pomeroy J, Azizian A. Comparison of DSM-IV symptoms in elementary school-age children with PDD versus clinic and community samples. Autism. 2005; 9(4): 392-415. DOI: $10.1177 / 1362361305056079$ [Link]

49. Eussen MLJM, Van Gool AR, Verheij F, De Nijs PFA, Verhulst FC, Greaves-Lord K. The association of quality of social relations, symptom severity and intelligence with anxiety in children with autism spectrum disorders. Autism. 2013; 17(6): 723-735. DOI: $10.1177 / 1362361312453882$ [Link]

50. Davis TE, Moree BN, Dempsey T, Hess JA, Jenkins WS, Fodstad JC, et al. The Effect of Communication Deficits on Anxiety Symptoms in Infants and Toddlers With Autism Spectrum Disorders. Behav Ther. 2012;43(1):142-52. DOI: 10.1016/J.BETH.2011.05. 003 [Link] 